\title{
Dysregulation of inflammation, neurobiology, and cognitive function in PTSD: an integrative review
}

\author{
Maria M. Quinones ${ }^{1}$ (D) $\cdot$ Autumn M. Gallegos ${ }^{2} \cdot$ Feng Vankee Lin $^{1,2,3} \cdot$ Kathi Heffner $^{1,2,4}$ \\ Published online: 13 March 2020 \\ (C) The Psychonomic Society, Inc. 2020
}

\begin{abstract}
Compelling evidence from animal and human research suggest a strong link between inflammation and posttraumatic stress disorder (PTSD). Furthermore, recent findings support compromised neurocognitive function as a key feature of PTSD, particularly with deficits in attention and processing speed, executive function, and memory. These cognitive domains are supported by brain structures and neural pathways that are disrupted in PTSD and which are implicated in fear learning and extinction processes. The disruption of these supporting structures potentially results from their interaction with inflammation. Thus, the converging evidence supports a model of inflammatory dysregulation and cognitive dysfunction as combined mechanisms underpinning PTSD symptomatology. In this review, we summarize evidence of dysregulated inflammation in PTSD and further explore how the neurobiological underpinnings of PTSD, in the context of fear learning and extinction acquisition and recall, may interact with inflammation. We then present evidence for cognitive dysfunction in PTSD, highlighting findings from human work. Potential therapeutic approaches utilizing novel pharmacological and behavioral interventions that target inflammation and cognition also are discussed.
\end{abstract}

Keywords Posttraumatic stress disorder $\cdot$ Inflammation $\cdot$ Neurobiology $\cdot$ Cognition $\cdot$ Intervention

\section{Introduction}

Posttraumatic stress disorder (PTSD) is a debilitating psychopathological consequence of exposure to a traumatic event and is associated with high rates of morbidity and mortality (Jakovljevic, Brajkovic, Loncar, \& Cima, 2012; Roberge, Dupuis, \& Marchand, 2010; Shalev, Liberzon, \& Marmar, 2017). The disorder is characterized by symptoms of intrusion, avoidance, persistent negative alterations in cognitions and mood, and alterations in arousal and reactivity (American Psychiatry Association, 2013). Patients with PTSD show

Maria M. Quinones

maria_quinones@urmc.rochester.edu

1 Elaine C. Hubbard Center for Nursing Research on Aging, School of Nursing, University of Rochester Medical Center, Rochester, NY 14642, USA

2 Department of Psychiatry, University of Rochester Medical Center, Rochester, NY, USA

3 Department of Neuroscience, University of Rochester Medical Center, Rochester, NY, USA

4 Division of Geriatrics \& Aging, Department of Medicine, University of Rochester Medical Center, Rochester, NY, USA persistent and intense fear reactions when exposed to situations associated with a previous traumatic event or that are contextually inappropriate, interpreting threat despite a safe context (Steiger, Nees, Wicking, Lang, \& Flor, 2015). In addition, persistent PTSD symptoms can be detrimental to physical and psychological health (McFarlane, 2010). Patients with PTSD report significantly more serious physical illnesses than their healthy counterparts, including more visits to the emergency department and primary care and higher rates of hospitalization and surgical procedures (Schnurr, 2015; Tuerk et al., 2013). Notably, comorbidity with other psychological diagnoses, such as depression and anxiety disorders, also tend to be higher with PTSD (Spinhoven, Penninx, van Hemert, de Rooij, \& Elzinga, 2014). To further highlight the complexity of PTSD, it remains unknown why many patients continue to experience persistent, unremitting symptoms of PTSD following trauma-focused interventions (Bradley, Greene, Russ, Dutra, \& Westen, 2005; Kearney \& Simpson, 2015; Schottenbauer, Glass, Arnkoff, Tendick, \& Gray, 2008; Steenkamp, Litz, Hoge, \& Marmar, 2015).

Compelling evidence suggests a strong link between inflammation and PTSD (Hori \& Kim, 2019; Mellon, Gautman, Hammamieh, Jett, \& Wolkowitz, 2018; Pace \& Heim, 2011). Moreover, a key feature of PTSD is 
compromised neurocognitive function mainly ascribed to deficits in attention and processing speed, executive function, and verbal learning and memory (Scott et al., 2015). Notably, some of these cognitive deficits may impact fear learning and extinction (Hofmann, 2008). Evidence suggests that central and peripheral inflammation can negatively impact cognition (Dantzer, O'Connor, Freund, Johnson, \& Kelley, 2008; Trapero \& Cauli, 2014). Thus, inflammatory dysregulation together with cognitive dysfunction potentially contribute to PTSD symptomatology. Surprisingly, very limited work has explored the interplay among these mechanisms in PTSD human research. This is of particular significance, given that a deeper understanding of the inflammatory and neurocognitive mechanisms underlying PTSD could guide the development of novel and clinically relevant interventions for individuals with PTSD.

The purpose of this review is to provide insight into the links between inflammation and cognitive dysfunction that may underpin PTSD symptoms. First, we briefly summarize evidence that suggests inflammatory dysregulation in PTSD, because this pathway has been reviewed extensively elsewhere (Hori \& Kim, 2019; Kim, Amidfar, \& Won, 2019; Mellon et al., 2018; Speer, Upton, Semple, $\&$ McKune, 2018). We further explore the existing literature on the neurobiological alterations in PTSD, specifically neurobiological underpinnings of the fear network and how inflammation may interact with these pathways. Then, we present evidence for significant cognitive dysfunction in PTSD and expand on findings in human work. Based on the evidence, we provide a novel model of combined inflammatory dysregulation and cognitive dysfunction that potentially contributes to PTSD development, progression, and maintenance. Finally, we describe pharmacological approaches and nontrauma-focused behavioral interventions that potentially target these dysregulated inflammatory, learning, and cognitive mechanisms as novel treatments for PTSD.

\section{Inflammation and PTSD}

Inflammation has played a central role in the understanding of PTSD. We provide a brief overview of the evidence for a proinflammatory profile in PTSD and refer the reader to more in-depth reviews of the inflammation and PTSD link (Jones \& Thomsen, 2013; Kim et al., 2019; Speer et al., 2018; Wang, Caughron, \& Young, 2017). PTSD is described as a state of chronic stress or hyperarousal, accompanied by elevated levels of proinflammatory cytokines (Passos et al., 2015). Patients with PTSD show significantly higher levels of common proinflammatory cytokines relative to non-PTSD trauma-exposed or healthy individuals, including interleukin (IL)- $1 \beta$, IL-6, tumor necrosis factor TNF- $\alpha$, interferon gamma (IFN-y), as well as the inflammation-stimulated acute phase protein, C-reactive protein (CRP) (Hussein, Dalton, Willmund, Ibrahim, \& Himmerich, 2017; Wang \& Young, 2016). Interestingly, peripheral levels of these proinflammatory markers have positively correlated with severity of PTSD symptoms and a greater probability to develop PTSD (Michopoulos, Powers, Gillespie, Ressler, \& Jovanovic, 2017). The link between a proinflammatory state and PTSD is further supported by emerging studies demonstrating associations between early life trauma exposure and increased inflammation that negatively affects the development of immune, neural, and cognitive systems (Baumeister, Akhtar, Ciufolini, Pariante, \& Mondelli, 2016; Danese \& Lewis, 2017; Delpech et al., 2016).

The most common underlying mechanisms implicated in PTSD-related inflammatory dysregulation are altered HPA axis and autonomic nervous system (ANS) function (Speer et al., 2018). Dysregulation of the HPA axis and its link to inflammation has been extensively studied in the field of PTSD (Dunlop \& Wong, 2019; Schumacher et al., 2019). Evidence suggests that the dysregulation occurs through increased sensitivity of the negative feedback mechanisms that regulate the HPA system, resulting in significantly lower levels of cortisol (Pan, Wang, Wu, Wen, \& Liu, 2018; van Zuiden, Kavelaars, Geuze, Olff, \& Heijnen, 2013). Of note, cortisol is a glucocorticoid (GC) with immunosuppressive and anti-inflammatory effects (Coutinho \& Chapman, 2011). Dysregulation of cortisol secretion further points to vulnerability to develop PTSD, as evidenced by lower levels of circulating cortisol before exposure to a traumatic event (Luo et al., 2012; van Zuiden et al., 2013). With low circulating cortisol, the immune system is left in a state of increased inflammatory activation (Daskalakis et al., 2016; Hori \& Kim, 2019). Thus, dysregulation of the HPA axis can contribute to a chronic low-grade inflammatory state in PTSD.

In the context of PTSD, dysregulation of the ANS is evidenced by a dominant sympathetic nervous system (SNS) and delayed reactivation of the parasympathetic nervous system (PNS) (Tan, Dao, Farmer, Sutherland, \& Gevirtz, 2011), which, in turn, can increase inflammation (Marvar \& Harrison, 2012). A promising area that has improved our understanding of ANS correlates of PTSD is the study of heart rate variability (HRV); yet, its link to inflammation has not been fully integrated into models of PTSD. HRV is the amount of change in heart rate across time and a key indicator of autonomic and physiological stress regulation (Kemp, Quintana, Felmingham, Matthews, \& Jelinek, 2012; Lehrer \& Gevirtz, 2014; Thayer, Yamamoto, \& Brosschot, 2010). Emerging evidence demonstrates that decreased HRV is observed in PTSD and is likely indicative of a hyperarousal state supported by lower vagal tone, resulting in lower parasympathetic cardiac control (Bandelow et al., 2017; Dennis et al., 
2014; Shah et al., 2013; Williamson, Porges, Lamb, \& Porges, 2014). Adequate vagal tone, as indexed by HRV, regulates inflammation (Pavlov \& Tracey, 2012) and is associated with lower levels of proinflammatory markers (Bonaz, Sinniger, \& Pellissier, 2016; Gerritsen \& Band, 2018). Thus, a reduction in parasympathetic drive, resulting in decreased HRV activity, may be one source of inflammation in PTSD. Future studies employing a multi-modal approach including measures of HRV (i.e., electrocardiogram) and neuroimaging to explore inflammatory processes in patients with PTSD would significantly improve our understanding of the links between ANS regulation, inflammation, and PTSD. In all, the dysregulation between the ANS and the innate immune system can be detrimental to neurobiological systems involved in the behavioral, cognitive, and emotional regulation capacity in patients with PTSD.

Despite the strong evidence linking inflammation and PTSD, findings are not fully consistent (Jergovic et al., 2015; McCanlies et al., 2011; Plantinga et al., 2013). The discrepancies in studies can be mostly attributed to a lack of uncontrolled potential confounders, lack of uniformity in PTSD assessment and biomarker collection methods, small sample sizes, and variations in comparable control groups (Michopoulos et al., 2017). Another potential source of variance is the high comorbidity of PTSD with depression. Translational models suggest that increased inflammation is implicated in depression (Amodeo, Trusso, \& Fagiolini, 2017; Lee \& Giuliani, 2019; Miller \& Raison, 2016), which could possibly confound associations between PTSD and inflammation. However, evidence also points to a distinct inflammatory profile when PTSD co-occurs with depression, that is, different from profiles observed in patients with PTSD alone (Gill, Luckenbaugh, Charney, \& Vythilingam, 2010; Passos et al., 2015). Similarly, traumatic brain injuries (TBI) are highly prevalent among populations with history of PTSD (i.e., veterans, IPV survivors), and findings suggest that inflammation may be an underlying mechanism of both conditions (Devoto et al., 2017; Rathbone, Tharmaradinam, Jiang, Rathbone, \& Kumbhare, 2015). Notably, findings further suggest that variability in TBI severity, such as presence or absence of LOC, may result in different proinflammatory profiles (Kanefsky et al., 2019). Thus, comorbidity of TBI and PTSD may also affect inflammatory trajectories in individuals with PTSD.

Overall, the previous findings support significantly elevated inflammation in PTSD. Despite the increasing support for a proinflammatory state in PTSD, it is important to note that inflammation is only one potential mechanism dysregulated in PTSD. Thus, we further consider how inflammation interacts with neurobiology in PTSD to suggest promising research avenues for elucidating the role of inflammation in PTSD.

\section{Neurobiology of the fear network and inflammation}

Fear conditioning and extinction is a useful model for understanding the intricate mechanisms involved in PTSD (Loayza Careaga, Neves Girardi, \& Suchecki, 2016). For decades, animal models have shed light on these mechanisms, offering great insight into the role of these behavioral processes and their neurobiological underpinnings in PTSD. Importantly, accumulative evidence suggests that dysregulation of the inflammatory response contributes to the impaired fear extinction observed in patients with PTSD (Schelling et al., 2006). Evidence from animal studies demonstrates that exposure to acute or chronic stress can lead to significant changes in the central nervous system centers that regulate the stress response (i.e., hypothalamus) and fear memories (i.e., amygdala; Jones \& Thomsen, 2013). Notably, upregulation of proinflammatory cytokines in these brain regions is observed following stress exposure (Johnson, Bernard, Kulp, \& Mehta, 2019; Vecchiarelli et al., 2016). Moreover, peripheral injection of lipopolysaccharide (LPS) in rodents results in an increased inflammatory response in fear circuit areas in the brain, specifically the amygdala (Prager et al., 2013), the prefrontal cortex (Yang et al., 2013), and the hippocampus (Kranjac et al., 2012), which are critical structures in the extinction process. The fear network has been extensively studied in animal models, and emerging evidence supports the application of this network to individuals with PTSD. We will first summarize relevant findings from animal work on the fear network. Then, we will discuss the application of the fear network to PTSD by expanding on human neuroimaging studies and also present evidence of how inflammation potentially interacts with this neurocircuitry in PTSD.

\section{Fear network in animal studies}

Animal studies provided the foundational understanding of the structural and functional connectivity within the fear network, identifying critical roles for the amygdala, medial prefrontal cortex (mPFC), and the hippocampus in mediating fear-related processes. Animal models of fear have consistently linked the amygdala to fear learning and subsequent expression of fear memory and to the process of extinction (Davis, Zaki, Maguire, \& Reijmers, 2017; Johansen et al., 2010). Given the complexity of the amygdala microcircuitry, studies with animals have identified differences in the activity of the amygdala subnuclei that are distinctly linked to fear processes. For example, interactions between the lateral (LA) and central (CeA) nuclei of the amygdala can increase or decrease fear responses, based on the centrolateral amygdala's inhibitory control of the centromedial amygdala (Hunt, Sun, Kucukdereli, Klein, \& Sah, 2017; Maeng \& Milad, 2017). 
Within the amygdala's microcircuit, the $\mathrm{CeA}$ is predominantly involved in the behavioral expression of conditioned fear responses (Ciocchi et al., 2010). Supporting these findings, Duvarci, Popa, and Paré (2011) showed that fear conditioning caused neurons in the CeA to increase their response to a conditioned stimulus, and their findings further suggest that expression of conditioned fear behavior depends on increased activity within the subnuclei of the $\mathrm{CeA}$. In addition, studies investigating neurons from the LA show potentiated responses to a tone that correlate with acquisition of fear and extinction learning (Herry et al., 2010; Pare \& Collins, 2000). In this regard, the evidence suggests that the LA is involved in associative learning and the retrieval of fearful memories (Elrich, Bush, \& LeDoux, 2012; Manassero, Renna, Milano, \& Sacchetti, 2018).

Studies on fear extinction further provide evidence of a link between the amygdala and the mPFC that is necessary for the process of fear extinction memory (Bloodgood, Sugam, Holems, \& Kash, 2018; Sotres-Bayon \& Quirk, 2010). Medial prefrontal cortex neurons elicit larger evoked potentials after fear extinction training in animals, further supporting the role of the mPFC in extinction (Garcia, Spennato, Nilsson-Todd, Moreau, \& Deschaux, 2008; Giustino \& Maren, 2015). In rodents, the prelimbic (PL) and infralimbic (IL) regions of the $\mathrm{MPFC}$ show distinct roles in the acquisition, expression, and extinction of conditioned fear. For example, PL activity is essential for the regulation of fear expression (Giustino \& Maren, 2015). Stimulation of the PL during exposure to a tone increased fear expression and impaired extinction learning (Vidal-Gonzalez, Vidal-Gonzalez, Rauch, \& Quirk, 2006), whereas inactivating this region before extinction training reduced fear expression during early extinction training (Sierra-Mercado, Padilla-Coreano, \& Quirk, 2011). In contrast, the IL region of the mPFC is consistently implicated in extinction learning (Godsil, Kiss, Spedding, \& Jay, 2013; Sotres-Bayon \& Quirk, 2010), with evidence also demonstrating that neuronal activity in IL further facilitates consolidation of extinction memory (Awad, Ferreira, \& Maroun, 2015). Notably, inactivating the IL region impairs retrieval of fear extinction resulting in recovery of fear conditioning (Vollmer et al., 2016). This suggests a role of the $\mathrm{mPFC}$ in recall of extinction memory as well.

Increasing evidence demonstrates that the hippocampus is a critical structure in contextual fear conditioning and extinction. Connections between the hippocampus and the amygdala, specifically the LA, appear to be essential to the acquisition and consolidation of contextual fear (Chaaya, Battle, \& Johnson, 2018). Models underscoring the acquisition of contextual fear memory suggest that fear memories are created when the hippocampus sends representations of contextual elements to the amygdala, which simultaneously receives somatosensory projections of aversive stimuli (Chaaya et al., 2018; Fanselow, 2010). In addition, fear extinction can be highly context dependent, with evidence suggesting further links to the hippocampus that support the recruitment of this region during extinction learning (Marek \& Sah, 2018). At the structural level, evidence shows that projections from the hippocampus to the $\mathrm{mPFC}$ can innervate neurons in the IL and PL that are active during the extinction process (Parent, Wang, $\mathrm{Su}$, Netoff, \& Yuan, 2010). Notably, when communication between the hippocampus and the mPFC is disconnected, this can fully disrupt contextual fear extinction (Zelikowsky et al., 2013).

In all, animal studies of fear extinction, demonstrating the critical involvement of a neural circuit of amygdala-mPFChippocampus, support the translatability of the fear network to the study of PTSD in humans. These studies identify key brain regions and connections that, when disrupted, may contribute to the development, progression, and maintenance of PTSD.

\section{Applying the fear network to human studies of PTSD}

In line with the findings of the "fear network" of amygdalamPFC-hippocampus from animal work, human neuroimaging studies also suggest critical roles for this network in PTSD. The amygdala, ventromedial prefrontal cortex (vmPFC), the anterior cingulate cortex (ACC), and the hippocampus have been identified as the key regions underlying the etiology, progression, and maintenance of PTSD (Fig. 1) (Linnman, Rougemont-Bücking, Beucke, Zeffiro, \& Milad, 2011; Maeng \& Milad, 2017; Milad \& Quirk, 2012). These regions are anatomically aligned with the fear network identified in the animal studies. Importantly, structural and functional connectivity within these brain regions support fear acquisition and extinction processes in humans (Pietrzak et al., 2015; Selemon, Young, Cruz, \& Williamson, 2019; Sherin \& Nemeroff, 2011). Notably, there is emerging evidence demonstrating that these brain regions interact with inflammation, which suggests novel PTSD intervention targets.

\section{Amygdala}

In humans, the amygdala has a pivotal role in the encoding of emotional memories and in the perception and processing of fear (Hermans et al., 2014). Consistent with animal models, increased activity in the amygdala is implicated in acquisition, consolidation, and extinction of fear in humans (Alvarez, Biggs, Chen, Pine, \& Grillon, 2008; Critchely, Mathias, \& Dolan, 2002; Milad et al., 2009; Roozendaal, McEwen, \& Chattarji, 2009). In studies using a conditioning and extinction paradigm, patients with PTSD relative to non-PTSD traumaexposed individuals show greater amygdala activation during exposure to an aversive stimulus (fear conditioning phase), as 

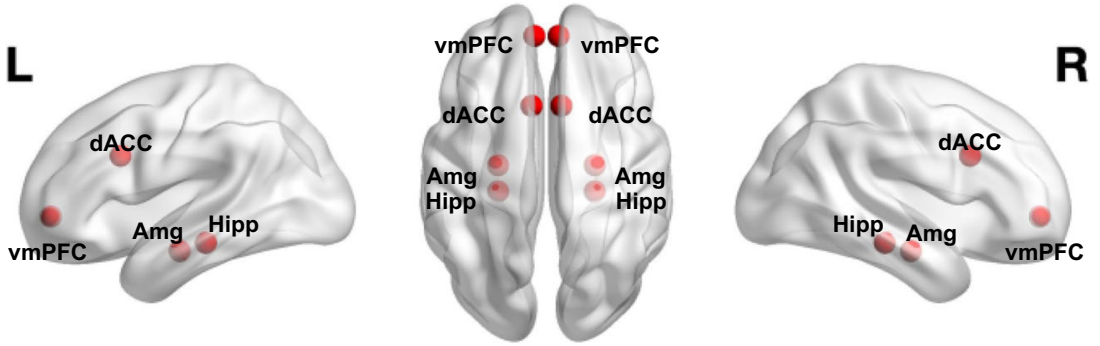

Fig. 1 Fear network in humans. The amygdala and the dACC exhibit robust activation during fear acquisition and expression. Extinction learning and recall of extinction memory are strongly associated with

well as during extinction training (Linnman, Zeffiro, Pitman, \& Milad, 2011). Supporting an active amygdala trend, patients with PTSD show greater resting amygdala activity before extinction training (Smith, Doran, Sippel, \& Harpaz-Rotem, 2017). Interestingly, patients with PTSD continue to display increased amygdala activity following extinction training compared with trauma-exposed participants without PTSD and healthy controls, suggesting enhanced fear recall in PTSD (Wicking et al., 2016). The increased activity of the amygdala may indeed prevail in PTSD and could potentially be associated with treatment-resistance or relapse of PTSD symptoms following treatment (Hayes, Hayes, \& Mikedis, 2012).

Of note, limited evidence in human studies show distinct changes within amygdala subnuclei related to PTSD. Recent findings show smaller lateral, paralaminar, and superficial amygdala nuclei volumes, but larger bilateral central, medial, and cortical nuclei in patients with PTSD relative to traumaexposed individuals without PTSD (Morey et al., 2019; Stein et al., 2019; Veer et al., 2015). Similarly, PTSD symptom severity was associated with an indentation in the centromedial amygdala within a sample of combat-exposed veterans with PTSD (Akiki et al., 2017). These findings further align with animal work and suggest amygdala subregionspecific patterns that are consistent with fear learning and expression in PTSD.

More recently, evidence suggests a bi-directional influence between inflammatory processes and amygdala activity. Neuroimaging studies reveal that increased amygdala response to stress is associated with production of IL-6 (Muscatell et al., 2015). Endotoxin-induced IL-6 and TNF- $\alpha$ production can further elicit greater amygdala activity in response to socially threatening stimuli (Inagaki, Muscatell, Irwin, Cole, \& Eisenberger, 2012). Notably, the inflammatory-induced increased activity of the amygdala potentially contributes to the increase in CRP production and hyperarousal in patients with PTSD (Michopoulos et al., 2015). More work is needed to directly examine the interactions between inflammation and the amygdala in the context of PTSD, as this area is presently understudied and may have further implications for PTSD interventions. reduced activity of the $\mathrm{vmPFC}$ and the Hipp. $\mathrm{vmPFC}=$ ventromedial prefrontal cortex; $\mathrm{dACC}=$ dorsal anterior cingulate cortex; $\mathrm{Amg}=$ amygdala; Hipp $=$ hippocampus

\section{Ventromedial prefrontal cortex}

Patients with PTSD also show distinct activity in the vmPFC (the human analog of the IL in rodents; Marek \& Sah, 2018). Reduced volume and activity of the vmPFC is one of the most consistently reported biomarkers for PTSD (Kuhn \& Gallinat, 2013). Typically, studies have focused on the contributions of the vmPFC to the extinction of conditioned fear, providing a direct correlation between the human vmPFC and the fear extinction process (Milad et al., 2005; Milad et al., 2009). While decreased regulatory activation of the $\mathrm{vmPFC}$ is linked to poor extinction learning, it also leads to deficient consolidation and recall of extinction memory (Phelps, Delgado, Nearing, \& LeDoux, 2004; Rougemont-Bucking et al., 2011). Conversely, vmPFC activity also is altered during acquisition and expression of fear (Shvil et al., 2014), suggesting that disrupted vmPFC activity may preclude the development of PTSD symptoms. Evidence also demonstrates a distinct pattern of increased activation of the vmPFC during fear conditioning, yet reduced activity during extinction learning among individuals with PTSD (Brown et al., 2014; Sripada et al., 2012). Interestingly, studies using other tasks unrelated to fear conditioning and extinction demonstrate negative correlations between vmPFC activation and PTSD symptom severity (Hughes \& Shin, 2011). This suggests that the reduced vmPFC activity may be more of a general functional property of this brain region in PTSD (VanElzakker, Dahlgren, Davis, Dubois, \& Shin, 2014).

Notably, increased inflammation is also associated with disrupted activity of the vmPFC (Kim et al., 2019). A previous study demonstrated that activation of the vmPFC during a grief-eliciting task in women undergoing bereavement stress was associated with increased TNF- $\alpha$ receptor II and IL-1 $\beta$ (O'Connor, Irwin, \& Wellisch, 2009). Although there is an existing gap in studies exploring the effects of inflammation on vmPFC activity in PTSD, it is possible that these inflammatory processes affect vmPFC activation, resulting in dysregulated emotional and cognitive processing in stress and trauma-related disorders (Felger, 2018). 


\section{Anterior cingulate cortex}

In recent years, findings from PTSD studies in humans provide links to the anterior cingulate cortex (ACC) and, most commonly, the dorsal ACC (dACC; homologue to the rodent PL). The dACC is associated with the appraisal and regulation of emotions as well as with increased attention bias to threat, serving further as a stress response pathway leading to downstream stimulation of the ANS, increasing sympathetic activity (Fani et al., 2012; Giuliani, Drabant, \& Gross, 2011; Tang et al., 2009). In humans, neuroimaging findings provide support that patients with PTSD exhibit smaller dACC volume, along with increased dACC activity being associated with the persistence of PTSD symptoms (Bromis, Calem, Reinders, Williams, \& Kempton, 2018; van Rooij, Kennis, Vink, \& Geuze, 2016). In addition, recent work shows that dACC task-related activity is also correlated with increased familial risk for PTSD development (Shin et al., 2011). Comparable to the activation of the amygdala, increased dACC activity is associated with the expression of fear and extinction processes (Bremner et al., 2005; Milad et al., 2009). During a fear conditioning trial, Rougemont-Bucking et al. (2011) found increased dACC activation in patients with PTSD, relative to a trauma-exposed control group without PTSD. Interestingly, the dACC showed sustained activity increases during fear conditioning (Linnman, Zeidan, Pitman, \& Milad, 2012) while resting-state metabolism in dACC was negatively correlated with extinction recall in nontrauma-exposed healthy participants (Linnman et al., 2012). Therefore, dACC signaling may promote continued fear expression and thus impair inhibition of the expression of fear response during extinction recall (Linnman, Zeidan, Furtak, et al., 2012).

The dACC is also highly susceptible to inflammationinduced dysregulation. Increased soluble and stimulated cytokine production positively correlated with greater activation in the dACC, amygdala, and PFC following exposure to a laboratory stressor (Muscatell et al., 2016; Slavich, Way, Eisenberger, \& Taylor, 2010). Earlier work in patients with hepatitis $\mathrm{C}$ virus showed that chronic administration of IFN- $\alpha$ resulted in increased dACC task-related activity and errors in a visuo-spatial attentional task (Capuron et al., 2005). Similarly, other studies have demonstrated associations among induced inflammation, poor cognitive outcomes, and dACC greater activity (Eisenberger, Lieberman, \& Satpute, 2005; Harrison et al., 2009a). Overall, inflammation appears to increase dACC activity, and this interaction may further contribute to greater PTSD symptoms and impaired learning and recall of extinction.
Hippocampus

Evidence from earlier human studies on PTSD suggested that the hippocampus is critical in the encoding and recognition of environmental cues during fear acquisition and extinction learning (Corcoran \& Maren, 2001; McEwen, 2000; Yehuda, 2002). Disrupted activity in hippocampal function can lead to failure to modulate contextual memories, thus rendering the individual with PTSD unable to distinguish between safe versus threatening contexts (Acheson, Gresack, \& Risbrough, 2012; Flor \& Wessa, 2010; Steiger et al., 2015). Indeed, the converging evidence proposes that deficient hippocampal function in PTSD at the time of trauma exposure can lead to a poor association of the context with the traumatic event (Acheson et al., 2012; Flor \& Wessa, 2010). This, in turn, leads to impaired fear memory and subsequent generalization of the fear expression to different contexts. In this regard, prior reduced hippocampal activity may be a preexisting vulnerability to develop PTSD. In line with these findings, decreased activation of the hippocampus also was found in patients with PTSD who failed to recall extinction (Milad et al., 2009), and the reduced activity may be linked to reduced hippocampal volume (Bremner, Elzinga, Schmahl, \& Vermetten, 2007). Patients with current PTSD have significantly smaller hippocampal volume (Apfel et al., 2011; Wang et al., 2010; Zhang et al., 2011), even when compared with trauma-exposed control individuals who do not have PTSD (Logue et al., 2018; Morey, Haswell, Hooper, \& De Bellis, 2016). Notably, greater hippocampal volume is associated with PTSD treatment response. Patients with PTSD who evidenced greater baseline hippocampal volume demonstrated greater treatment gains following exposure therapy, suggesting that greater hippocampal volume potentially facilitates a more robust fear-extinction capacity (Rubin et al., 2016). The observed changes in hippocampal volume in PTSD, however, appear to be widespread and inconsistent as findings report reduced volume in posterior (Bonne et al., 2008), right and left (Woon, Sood, \& Hedges, 2010) hippocampus.

Increased inflammation plays a pivotal role in hippocampal dysfunction and atrophy (Chesnokova, Pechnick, \& Wawrowsky, 2016; Tsai, 2017). Positron emission tomography (PET) on healthy individuals demonstrated a reduction in parahippocampal and rhinal glucose metabolism following typhoid vaccination (Harrison, Doeller, Voon, Burgess, \& Critchley, 2014). Additionally, in a study conducted with veterans, increased soluble receptor II for TNF- $\alpha$ was significantly associated with reduced hippocampal volume, and this association was stronger with greater PTSD severity (O'Donovan et al., 2015). Overall, the inflammatory-induced hippocampal atrophy and dysfunction has significant clinical implications for 
patients with PTSD, as it potentially leads patients to fail to discriminate between dangerous and safe contexts following extinction training.

\section{Functional connectivity of the amygdala-vmPFC-ACC-hippocampus circuit}

Functional abnormalities in the fear network suggest a general neurocircuitry dysfunction in PTSD (VanElzakker et al., 2014). Evidence from neuroimaging studies provide a predominant framework of disrupted network connectivity, supporting a top-down regulation of temporal structures (i.e., amygdala and hippocampus) by frontal regions in PTSD (Phelps et al., 2004). Patients with PTSD show markedly reduced vmPFC activity that correlates with increased amygdala activity (Hayes, Hayes, \& Mikedis, 2012), demonstrating the consistency of this brain activation pattern in the fear network in PTSD (Maeng \& Milad, 2017). Exposure to fearful stimuli significantly decreased task-related functional connectivity between the right amygdala and the vmPFC among those with PTSD (Stevens et al., 2013). In healthy participants, activation of the dACC and deactivation of vmPFC metabolism significantly correlated with higher resting amygdala activity, further supporting an inhibitory role of the vmPFC on the amygdala's fear expression and the dACC's role in promoting it (Linnman, Zeidan, Furtak, et al., 2012). In addition, PTSD symptom severity, particularly hyperarousal, is associated with negative mPFC-amygdala coupling (Sadeh, Spielberg, Warren, Miller, \& Heller, 2014). Few studies have examined brain functional connectivity during fear conditioning and extinction in PTSD samples. Evidence from healthy individuals suggests that concurrent activation of the amygdala and the hippocampus may be important for contextual fear learning (Baeuchl, Meyer, Hoppstadter, Diener, \& Flor, 2015; Knight, Smith, Cheng, Stein, \& Helmstetter, 2004). Notably, during extinction recall, brain activation patterns are consistent with vmPFC and hippocampal reduced activity, further demonstrating a role for these brain regions in the contextual modulation of fear extinction and thus contributing to contextual processing deficits (Garfinkel et al., 2014; Milad et al., 2007). The reduced activity of the vmPFC and hippocampus together with the increased activity of the amygdala and dACC may indeed underlie the impaired extinction processes observed in patients with PTSD (Sheynin \& Liberzon, 2017).

Little is known about the contributions of inflammation to altered functional connectivity in PTSD; however, existing findings suggest possible implications for understanding psychiatric disorders. For example, IL-6 response to typhoid vaccination decreased mood in a sample of healthy men, and this inflammation-associated mood change correlated with reduced connectivity between the $\mathrm{ACC}$ and the amygdala and mPFC (Harrison et al., 2009b). Similarly, increased CRP predicted decreased functional connectivity between right amygdala and left vmPFC in patients with comorbid depression and anxiety (Mehta et al., 2018). Consistent with these findings, a recent study reported an indirect effect of IL6 that partially mediated the association between childhood physical abuse and reduced adult amygdala-vmPFC connectivity (Kraynak, Marsland, Hanson, \& Gianaros, 2019). The dissociation in frontotemporal activity coupled with increased inflammation could potentially result in difficulties with behavior and emotion regulation, and cognition in patients with PTSD and related comorbidities, such as depression.

Taken together, these findings support an interplay between inflammation and the amygdala-vmPFC-ACC-hippocampus circuit that further supports fear conditioning and extinction learning and recall. The recent advances in the field of PTSD suggest that the activity and functional connectivity of these brain regions also appears to be compromised in PTSD and vulnerable to the effects of inflammation. Thus, the emerging evidence may trace an inflammatory-neural pathway that is relevant for PTSD development, maintenance, and progression. Future studies are required using emerging cutting-edge imaging techniques (i.e., PET) to address this neuroinflammatory interplay and identify specific inflammation-associated neural biomarkers of PTSD. This would provide more direct evidence for the associations among inflammation and PTSD, and, in turn, it would advance the field by allowing to test the effects of novel interventions on central inflammatory-related processes in patients with PTSD.

Of note, the amygdala, PFC, ACC, and hippocampus are also central to cognition and consistently implicated in attention, processing speed, executive function, and memory. Notably, some of these cognitive processes also may impact fear conditioning and extinction (Hofmann, 2008). Thus, the potential dysregulation of inflammation, together with disrupted neural connectivity could have further detrimental implications for cognitive function and, subsequently, its contributions to persistent PTSD symptoms.

\section{Cognitive deficits in posttraumatic stress disorder}

In addition to an increased inflammatory response and altered neurobiological pathways, cognitive deficits are strongly linked to PTSD. Given the bi-directional links between cognition and emotions, cognitive deficits may play a central role in PTSD development, maintenance, or severity, and thus negatively impact treatment (Hayes, Vanelzakker, \& Shin, 2012). Studies in PTSD provide strong evidence for memory dysfunction, while deficits in attention and processing speed and executive function have gained more recent empirical 
attention (Koso \& Hansen, 2006; Latack, Moyer, Simon, \& Davila, 2017; Scott et al., 2015). The association between PTSD and cognition can be bi-directional, as cognitive deficits can result as part of the pathophysiology of PTSD, or they can potentially be a risk factor for PTSD (DiGangi et al., 2013; Sumner et al., 2017; Twamley et al., 2009).

Accumulating evidence shows that elevated central and peripheral inflammation can have detrimental effects on cognition (Gruol, 2015; Swardfager et al., 2010; Tangestani Fard \& Stough, 2019; Trapero \& Cauli, 2014; Walker et al., 2019). Increased inflammation is associated with poor cognitive function in mental health disorders, including depression (Charlton et al., 2018; Krogh et al., 2014) and anxiety (Salim, Chugh, \& Asghar, 2012). Inflammation contributes to the regulation of neuronal, molecular, and cellular processes underlying cognitive function, including neuroplasticity, neurogenesis, and long-term potentiation (Yirmiya \& Goshen, 2011). Conversely, inflammatory dysregulation can disrupt these immune-regulatory processes that support cognition and, in turn, affect cognitive function (Calabrese et al., 2014; Lin et al., 2018). Findings from animal work demonstrate that inflammation plays a central role in the neurocognitive underpinnings of PTSD symptoms, including fear learning and impaired extinction (Doenni, Song, Hill, \& Pittman, 2017; Kranjac et al., 2012; Lisboa et al., 2018; Quinones, Maldonado, Velazquez, \& Porter, 2016; Sparkman, Kohman, Garcia, \& Boehm, 2005). There is very limited knowledge, however, about the interplay between inflammation and cognitive function in human studies of PTSD, leaving a critical gap in our understanding of this disorder. A recent cross-sectional study found that women with PTSD showed significantly higher levels of IL-6 and poor overall cognitive performance (Imai et al., 2018). Given that the evidence suggests that inflammation is a key component of PTSD and it further interacts with fear learning and extinction-related neural pathways, it is possible that these interactions also contribute to the reduced cognitive function in patients with this disorder.

\section{Attention and processing speed of information}

Recent evidence suggests that deficits in attention and processing speed are closely linked to the progression of PTSD (Aupperle, Melrose, Stein, \& Paulus, 2012; Qureshi et al., 2011). Notably, inflammation has been associated with deficits in attention and slow processing speed (Beydoun et al., 2019), further underscoring the potential interplay of these inflammatory and cognitive mechanisms in PTSD etiology, progression, or severity. The severity of PTSD symptoms is strongly associated with poor performance on attention tasks (Dutra, Marx, McGlinchey, DeGutis, \& Esterman, 2018), up to a year following exposure to a traumatic event (Marx et al., 2009). Most frequently, PTSD symptoms correlate with deficits in sustained and selective attention (Vasterling et al., 2002). Indeed, elevated symptoms of PTSD have correlated with a marked reduced ability to resist distractors (Esterman et al., 2013). Additionally, PTSD symptom severity can further impact the ability to maintain attention to task-relevant stimuli (Brownlow, Brown, \& Mellman, 2014) and screen out irrelevant information, a difficulty that is not confined to specific trauma-related stimuli (Shucard, McCabe, \& Szymanski, 2008). Together, these findings suggest deficits in the attentional control required to disengage attention from trauma-related stimuli in patients with PTSD (Ashley, Honzel, Larsen, Justus, \& Swick, 2013).

Patients with PTSD also perform worse on timed tasks compared with their healthy counterparts, suggesting slow processing speed of information. One study showed that participants who met full criteria for PTSD scored significantly worse on processing speed, after adjusting for demographics (Cohen et al., 2013). However, when accounting for health behaviors, vascular risk factors, and depression, this association was reduced by $12 \%$ but remained significant nonetheless. Similar findings were previously reported when controlling for alcohol consumption, educational level, and depression, demonstrating that PTSD was independently associated with decreased performance on measures of attention and processing speed (Samuelson et al., 2006). While these studies suggest that PTSD may have independent links to poor cognition, others conclude that comorbidity of PTSD with inflammatory conditions (i.e., TBI) indeed worsens cognitive deficits, including processing speed and attention, further complicating cognitive outcomes in individuals with PTSD (Combs et al., 2015). Of note, in a sample of women who experienced intimate partner violence (IPV), severity of PTSD symptoms was associated with worse performance on speed tasks and, interestingly, on executive function tasks with only a time component, suggesting that slow processing speed confounded performance on measures of executive function (Twamley et al., 2009). Overall, this slowing of processing speed of information in patients with PTSD may be attributable to reduced attentional resources due to active cognitive efforts being directed toward coping with psychological distress (DePrince \& Freyd, 2004).

Complementing these findings, attentional and information processing networks in patients with PTSD show disproportionate activation patterns in response to threat versus nonthreat-related content (Bryant et al., 2005). Recently, a study suggested a global brain network mechanism that traces both PTSD clinical symptoms and PTSD-related deficits in attention (Zhu et al., 2019). Their results demonstrated that increased functional segregation of the Default Mode Network and the occipital cortex are associated with sustained attention in patients with PTSD. Given that attention, processing speed, and learning may interact via frontocortical 
pathways (Leong, Radulescu, Daniel, DeWoskin, \& Niv, 2017; Woodward, Duffy, \& Karbasforoushan, 2013) and frontal connectivity is highly sensitive to inflammation, the combined effects of inflammation and attentional and processing speed deficits potentially play a role in shaping traumatic memories.

\section{Executive function}

Consistent with a neurobiological profile of disrupted prefrontal connectivity and poor prefrontal-mediated task performance linked to inflammation (Marsland et al., 2006), PTSD also is associated with deficits in executive function (Polak, Witteveen, Reitsma, \& Olff, 2012). Patients with PTSD show poor performance, with strong effects sizes, on measures of executive function compared with trauma-exposed individuals who do not develop PTSD (Hart Jr. et al., 2008). In a recent sample of individuals exposed to war and political violence, current levels of PTSD symptoms correlated with deficits in executive function 20 years after exposure to the trauma (Blanchette, Rutembesa, Habimana, \& Caparos, 2019). The long-term effects of trauma exposure on executive function also are supported by evidence from survivors of natural disasters with a previous, but not current, diagnosis of PTSD. Individuals continued to show impaired cognitive flexibility and verbal fluency, further supporting sustained deficits in prefrontal organization (Eren-Kocak, Kilic, Aydin, \& Hizli, 2009). Comorbidity with other psychiatric disorders can exacerbate these deficits, which can lead patients to become more treatment-resistant. For example, patients with PTSD with comorbid depression show greater impairment on multiple measures of executive function (Jurick et al., 2018). Interestingly, in depression coupled with childhood trauma, elevated levels of peripheral cytokines were distinctly associated with executive dysfunction (Peters et al., 2019). Given that executive function deficits, and inflammation, also are a hallmark of depression (Baune et al., 2018; Beblo, Sinnamon, \& Baune, 2011; Bortolato, Carvalho, \& McIntyre, 2015), comorbidity with PTSD can complicate a patients' clinical profile offering a very poor prognosis and little treatment gains.

Although there is ample evidence concerning impaired executive function in PTSD, it remains unclear which aspects of executive function become more compromised (Crowell, Kieffer, Siders, \& Vanderploeg, 2002; Leskin \& White, 2007; Twamley et al., 2009) or whether there is a global executive dysfunction in PTSD (Park et al., 2018). Previous findings further suggest that exposure to trauma itself, and not PTSD, suffices to develop deficits in executive function. For example, survivors of IPV evidenced worse performance on tasks of working memory and inhibition, regardless of the presence of a PTSD diagnosis (Stein, Kennedy, \& Twamley, 2002). There is, however, converging evidence showing that
PTSD is most strongly associated with deficits in inhibition, that is, difficulties with inhibiting automatic or inappropriate responses (Casada \& Roache, 2005; Clausen et al., 2017; Contractor, Elhai, Ractliffe, \& Forbes, 2013; Shucard et al., 2008; Sijbrandij, Engelhard, Lommen, Leer, \& Baas, 2013; Wu et al., 2015). Studies with veterans demonstrate that higher PTSD symptoms strongly correlate with worse performance on inhibition tasks to a greater extent than other executive function domains, such as task switching, cognitive flexibility, and working memory (Campbell et al., 2009; DeGutis et al., 2015; Nelson, Yoash-Gantz, Pickett, \& Campbell, 2009; Swick, Honzel, Larsen, Ashley, \& Justus, 2012). In line with these findings, the stability of cognitive control processes - as indexed by variability in reaction time of behavioral responses - appears to be compromised in patients with PTSD as well. In a sample comparing individuals with and without PTSD, greater variability in response time during a response inhibition task was evidenced only among those with PTSD (Swick, Honzel, Larsen, \& Ashley, 2013). This variability in reaction time was further associated with selfreported symptoms of PTSD and attentional impulsiveness. Notably, there is a possibility of a bi-directional relationship between deficits on inhibition and PTSD. Preexisting deficits with inhibitory control could lead to difficulties with disengaging from trauma-related memories and cues, increasing the likelihood of developing and maintaining PTSD (Aupperle et al., 2012). Conversely, symptoms of PTSD, such as intrusion and hypervigilance, further decrease the ability to inhibit behavioral and emotional responses. Overall, these findings support a model of impaired inhibitory control in PTSD, consistent with deficits in top-down cognitive control processes, which could potentially explain the observed difficulties in behavior and emotion regulation in patients with PTSD (Aupperle et al., 2012; Hayes, VanElzakker, \& Shin, 2012).

Aside from its critical role in daily functioning, adequate executive function is required to benefit from interventions that rely on cognitive processes to facilitate emotion regulation and changing maladaptive thoughts and behaviors (Falconer, Allen, Felmingham, Williams, \& Bryant, 2013; Jak et al., 2015). Thus, deficits in executive function or underlying inefficient inhibitory neural network connectivity could decrease the effectiveness of common trauma-focused, evidence-based interventions for PTSD. Executive function deficits also could damper the effects of pharmacological treatment on PTSD symptoms. For example, in patients with major depression, greater deficits in executive function predicted poorer treatment response to antidepressant medication (Pimontel et al., 2016; Sneed et al., 2010). Particularly, response inhibition appears to be a specific aspect of executive function that negatively impacts antidepressant response rate (Pimontel, Culang-Reinlieb, Morimoto, \& Sneed, 2012; Sneed et al., 2007). Although some speculate that antidepressants, the pharmacological treatment of choice for PTSD, 
exert anti-inflammatory effects (Galecki, MossakowskaWojcik, \& Talarowska, 2018), these effects may not be sufficiently significant to mitigate the interaction between inflammation and executive dysfunction. Thus, executive deficits may persist, despite intervening on clinical mood and behavioral symptoms. In sum, unattended executive function deficits may lead to poor treatment response and outcomes.

\section{Memory}

Memory deficits in PTSD have been extensively studied both in animal and human work. A wealth of literature further supports a critical role of inflammatory signaling in learning and memory (Donzis \& Tronson, 2014). Thus, inflammatoryrelated PTSD pathophysiology may play a key role in memory deficits, which are among the most common cognitive disturbances in PTSD. We provide only a brief review about relevant work attempting to clarify the associations between PTSD and memory function. Hippocampal dysfunction can lead to loss of context sensitivity of the fear conditioned response and result in memory deficits leading to poor integration of the traumatic event in patients with PTSD (Wolf, 2008). Earlier human and animal studies on the associations between memory dysfunction and PTSD reported impairments in both acquisition and recall related with a reduced ability to consolidate memory (Bremner, Vermetten, Afzal, \& Vythilingam, 2004; Diamond, Fleshner, Ingersoll, \& Rose, 1996; Gilbertson, Gurvits, Lasko, Orr, \& Pitman, 2001; Golier, Harvey, Legge, \& Yehuda, 2006; Luine, Villegas, Martinez, \& McEwen, 1994). The most commonly reported deficits in memory function in patients with PTSD are deficits in episodic memory (Golier \& Yehuda, 2002; Golier et al., 2006; Samuelson, 2011; Zlomuzica et al., 2018), with some evidence suggesting difficulties with visual (Aase et al., 2017; Sierk et al., 2019) and autobiographical memory (Dalgleish, Rolfe, Golden, Dunn, \& Barnard, 2008; Wessel, Merckelbach, \& Dekkers, 2002). Deficits in memory also may predict treatment outcomes with behavioral interventions. Patients with PTSD who did not respond to Cognitive Behavioral Therapy performed significantly worse on measures of verbal memory compared with responders and further demonstrated deficits in narrative encoding (Wild \& Gur, 2008).

There is speculation that memory dysfunction can be attributable to deficits in other cognitive domains. For example, because difficulties in the ability to suppress involuntary thoughts in PTSD can reflect a general failure in executive control, it is possible that these deficits in turn confound results on specific memory tests involving organizational strategies and executive control (Johnsen \& Asbjornsen, 2009). In addition, although several studies support deficits in learning and memory tasks in PTSD, minimal forgetting occurs over time, and individuals can typically recall information during a recognition trial, minimizing demands on retrieval (Cohen et al., 2013; Jenkins, Langlais, Delis, \& Cohen, 1998; Johnsen, Kanagaratnam, \& Asbjornsen, 2008). This further suggests that memory deficits in PTSD are associated with difficulties in strategic encoding and retrieval of information, showing that prefrontal pathways also contribute to memory deficits in PTSD (Brewin, Kleiner, Vasterling, \& Field, 2007; Lagarde, Doyon, \& Brunet, 2010; Samuelson et al., 2006; Twamley et al., 2009). Further supporting this proposition, recent evidence suggests that disruption of the PFChippocampal circuitry contributes to cognitive dysfunction, including memory, in depression and Alzheimer's disease (Sampath, Sathyanesan, \& Newton, 2017), both of which are considered inflammatory-related neuropsychiatric conditions. Another assumption is that deficits in attention lead to the observed dysfunction in encoding. To address this, studies have controlled for attention and the effect of total learning in select memory tasks and have provided evidence suggesting that memory deficits in PTSD are not in fact secondary to attentional dysfunction (Gilbertson et al., 2001; Yehuda, Golier, Halligan, \& Harvey, 2004; Yehuda, Golier, Tischler, Stavitsky, \& Harvey, 2005). An additional concern raised from studies examining memory deficits in PTSD is that these have been conducted on groups with comorbid psychiatric disorders. While some studies controlling for comorbidity suggest that PTSD has an independent effect on memory (Bremner et al., 2004; Jelinek et al., 2006; Sierk et al., 2019), others have found that depression, in particular, contributes to the memory dysfunction and overall cognitive deficits in PTSD (Brandes et al., 2002; Burriss, Ayers, Ginsberg, \& Powell, 2008; Johnsen \& Asbjornsen, 2009; Johnsen et al., 2008).

Overall, these findings support a model of increased inflammation and compromised neurocognitive function in PTSD. Future longitudinal studies with comprehensive and standardized measures are needed to further elucidate the interplay among inflammation and cognition in PTSD. These longitudinal studies should further attempt to clarify the role of potential confounding factors in this interplay, such as depression considering its high comorbidity rates and its potential inherent inflammatory and cognitive dysregulation. Additionally, given the bi-directional influences between inflammation and cognition, it is worth exploring how lower cognitive function at the onset of PTSD moderates inflammatory trajectories and PTSD symptom progression. This would provide guidance for additional cognitive targets and strategies to address during intervention development.

\section{Novel pharmacological and behavioral interventions for PTSD}

The evidence presented thus far suggest that dysregulated inflammation and cognition may together contribute to the 
development, progression, or severity of PTSD. In line with this proposition, targeting these mechanisms could offer novel treatment approaches for patients with PTSD. Current standard treatments for PTSD include both pharmacological and psychological interventions. We will briefly overview the support for novel pharmacological approaches (i.e., angiotensin receptor blockers and angiotensin-converting enzyme inhibitors) and behavioral interventions (i.e., mindfulness-based interventions, computerized cognitive training, heart rate variability biofeedback, and exercise) that may mitigate PTSD symptoms through their effects on inflammation and cognitive dysfunction. Notably, as described below, some of these interventions target inflammation and/or cognitive dysfunction. While inflammation can lead to structural and functional brain changes that impact cognitive function, inversely, poor cognitive function also can upregulate inflammation. Thus, targeting inflammation or cognitive function may potentially disrupt the bi-directional pathways contributing to PTSD symptoms and severity.

\section{Novel pharmacological interventions for PTSD}

The current evidence base for pharmacological treatment for PTSD is strongest for selective serotonin reuptake inhibitors (SSRIs), which are recommended as second-line treatment for patients who do not engage in or cannot access traumafocused psychotherapies (Hoskins et al., 2015; Lee et al., 2016). Pharmacotherapy with SSRIs is most effective in decreasing hyperarousal and mood (irritability, anger, depression) symptoms of PTSD, but these have been less effective for the symptoms of reexperiencing, emotional numbing, and behavioral avoidance (Stein, Ipser, Seedat, Sager, \& Amos, 2006). Here, we consider a novel pharmacological approach for PTSD to address underlying mechanisms that remain untargeted with current interventions. Recent evidence suggests that angiotensin receptor blockers (ARBs) and angiotensin-converting enzyme (ACE) inhibitors, which are common hypertensive medications, may exert antiinflammatory properties and benefit cognitive function. The renin-angiotensin system (RAS) controls blood pressure and electrolyte balance, mainly by action of the octapeptide angiotensin II ([AngII]; Oliveira et al., 2007). AngII can induce cytokines and chemokines, possibly by activation of NF-кB (Pham, Chong, Vincenti, \& Slice, 2008), that are important in recruiting leukocytes to sites of inflammation, thereby implicating AngII as a proinflammatory molecule (Benigni, Cassis, \& Remuzzi, 2010; Chang \& Wei, 2015). Treatment with ARBs and ACEs potentially prevents and reverses the neural and behavioral effects of inflammation. In an animal paradigm of PTSD, subchronic administration of candesartan, an ARB that centrally and peripherally blocks AngII activity at AngII receptor type 1 (AT1), prevented LPS-induced impairment of extinction learning and recall (Quinones et al., 2016). Evidence from human studies suggest protective effects of ARBs against cognitive impairment related to inflammatory diseases. Patients with Alzheimer's disease and vascular dementia taking ARBs showed a reduced progression of cognitive decline compared to patients not taking any ARBs (Chiu et al., 2014). Treatment with ARBs and ACEs also can improve PTSD symptoms among individuals exposed to trauma: lower symptoms of PTSD have been reported among individuals taking ARBs, and ACEs (Nylocks et al., 2015), specifically, reduced severity of intrusive and hyperarousal symptoms (Khoury et al., 2012). Overall, these findings suggest that targeting the RAS can have implications on inflammatory and cognitive outcomes and may well provide a novel pharmacological intervention for the treatment of PTSD.

\section{Nontrauma-focused behavioral interventions for PTSD}

Trauma-focused behavioral treatments have the strongest evidence of effectiveness, specifically cognitive processing therapy (CPT), prolonged exposure (PE), and eye movement desensitization and reprocessing ([EMDR]; Bisson, Roberts, Andrew, Cooper, \& Lewis, 2013; Lee et al., 2016), and are recommended as the first-line treatment for PTSD. These behavioral interventions are based on the fear-learning model of PTSD, namely abnormalities in extinction of fear and safety learning (Shalev et al., 2017), and therefore target traumarelated beliefs, memories, and emotions. Despite their efficacy, these interventions have high rates of incompletion (up to $50 \%$ ), and many patients continue to have residual symptoms following treatment (Bradley et al., 2005; Kearney \& Simpson, 2015; Schottenbauer et al., 2008; Steenkamp et al., 2015). As such, researchers are increasingly investigating the use of nontrauma-focused behavioral interventions for PTSD. A handful of such interventions show particular promise for targeting the cognitive, neural, and inflammatory pathways underscored by this review.

As noted previously, deficits in executive control contribute to the development and maintenance of PTSD (LoSavio, Dillon, \& Resick, 2017; Swick, Cayton, Ashley, \& Turken, 2017). Recent findings also demonstrate that worse executive control predicts increased inflammatory reactivity to emotional distress (Shields, Kuchenbecker, Pressman, Sumida, \& Slavich, 2016). This would suggest that targeting executive control may impact both cognitive and inflammatory pathways linked to PTSD. Mindfulness-based interventions (MBIs) may offer a novel approach to target these mechanisms. Mindfulness-based interventions train focused attention, which is the practice of sustaining attention on a chosen object, such as breath, while remaining attentive to the present 
moment without judgment or emotional reactivity (Jha, Stanley, Kiyonaga, Wong, \& Gelfand, 2010). Previous evidence demonstrates that mindfulness practice improves executive control ability (Fabio \& Towey, 2018; Hofmann et al., 2019; Teper, Segal, \& Inzlicht, 2013), possibly through attentional training-related changes in frontal, parietal, and temporal brain regions (Li, Liu, Zhang, Liu, \& Wei, 2018; Taren et al., 2017). Indeed, MBIs can modulate PFC-amygdala connectivity (Holzel et al., 2011) and further improve attention and executive control in populations without PTSD (Desrosiers, Vine, Klemanski, \& Nolen-Hoeksema, 2013; Goldin \& Gross, 2010; Tang, Tang, Tang, \& Lewis-Peacock, 2017). In addition, a recent study of an MBI for emotionally distressed adults showed reduced IL-6 levels from baseline to 4-month follow-up and that pretraining to posttraining changes in frontal brain cortices implicated in attention and executive control mediated the effects on IL-6 (Creswell et al., 2016). In general, randomized, clinical trials of MBIs provide empirical evidence of significant decreases in markers of inflammation and improved PTSD symptoms, including reductions in intrusion, avoidance, and arousal (Bergen-Cico, Possemato, \& Pigeon, 2014; Black \& Slavich, 2016; Davis et al., 2018; Gallegos, Crean, Pigeon, \& Heffner, 2017; Heffner, Crean, \& Kemp, 2016). These findings lend support for cognitive and inflammatory targets of MBIs that may shed light on how these interventions may be further developed and leveraged to treat PTSD symptoms.

Computerized cognitive training (CT) is a novel approach to potentially improve cognition, inflammation, and symptoms of PTSD. Computerized CT involves structured practice on standardized and cognitively challenging tasks (Lampit, Hallock, \& Valenzuela, 2014). Currently, evidence shows that CT improves cognition and mood symptoms in depression (Morimoto, Wexler, \& Alexopoulos, 2012; Motter et al., 2016; Owens, Koster, \& Derakshan, 2013; Semkovska \& Ahern, 2017; Wolinsky et al., 2009). In a randomized, controlled trial (RCT) of a computerized CT intervention for women with PTSD following exposure to sexual violence, training interference control improved working memory capacity and decreased reexperiencing symptoms (Bomyea, Stein, \& Lang, 2015). In addition, improvements in cognitive flexibility - a domain implicated in executive controlresulting from 30 days of $\mathrm{CT}$ in trauma-exposed individuals were associated with lower PTSD symptoms 6 months after trauma exposure (Ben-Zion et al., 2018). It is possible that targeting cognition may strengthen connectivity of frontal regulatory areas in the brain leading efferent projections from frontal cortices to modulate subcortical cells known to trigger peripheral inflammatory responses (Cisler et al., 2013; Creswell et al., 2016; Gross, 2002; Irwin \& Cole, 2011). Both computerized CT and MBIs potentially offer a topdown regulatory pathway for the modulation of circulating cytokines by strengthening functional connectivity of frontal regulatory areas associated with cognitive control and emotion regulation, and thus, warrant further research.

Heart rate variability is another promising target of behavioral intervention for PTSD. As noted previously, PTSD is associated with reduced HRV (Nagpal, Gleichauf, \& Ginsberg, 2013; Tan et al., 2011). Importantly, there are links between HRV and cognitive-emotion processes that are relevant to PTSD. Evidence supports HRV as a peripheral index of the integrity of neural structures that underpin inhibitory control and more broadly regulate cognitive, emotion, and physiological responses to support goal-directed behavior. For example, the high-frequency domain of HRV (HF-HRV), reflecting vagal control of the heart, is positively related to working memory, sustained and selective attention, cognitive flexibility, and inhibition (Park, Vasey, Van Bavel, \& Thayer, 2013; Thayer, Hansen, Saus-Rose, \& Johnsen, 2009). Poor inhibition is a key mechanism by which individuals with PTSD produce context-inappropriate responses, including situationally inappropriate hypervigilance and interpreting threat despite a safe context (van Rooij, Geuze, Kennis, Rademaker, \& Vink, 2015). Not surprisingly, poor inhibition is associated with reduced HRV in PTSD (Gillie \& Thayer, 2014).

Given these links, heart rate variability biofeedback (HRVB) has received attention as an approach to modulating cognitive-emotional pathways in PTSD. HRVB entails breathing training to maximize respiratory sinus arrhythmia (RSA) - the synchronization of HR change (increases/decreases) with respiratory (inhalation/exhalation) patternsand activity of the baroreflex, resulting in "bottom-up" modulation of autonomic response via the parasympathetic nervous system ([PNS]; Barlow, Lehrer, Woolfolk, \& Sime, 2007; Lehrer, 2018). This activity supports regulation of cognition, physiological stress, and emotion (Beauchaine, Gatzke-Kopp, \& Mead, 2007; Friedman, 2007; Goessl, Curtiss, \& Hofmann, 2017; Lehrer et al., 2003).

Randomized, clinical trials of HRVB with PTSD populations have demonstrated significant reductions in PTSD symptom severity following HRVB (Tan et al., 2011; Zucker, Samuelson, Muench, Greenberg, \& Gevirtz, 2009). HRVB interventions with nontrauma populations have demonstrated beneficial effects on cognition, including improved attentional skills and executive function (Jester, Rozek, \& McKelley, 2019; Prinsloo et al., 2011). However, results are less clear for its effects on inflammation. While HRVB appears to reduce inflammation-induced decline in HRV (Lehrer et al., 2010), possibly through PNS modulation of the cholinergic anti-inflammatory system (Gevirtz, 2013; Huston \& Tracey, 2011), HRVB did not affect cytokine production. In all, HRVB may offer a novel bottom-up regulatory intervention to target these cognitive and inflammatory mechanisms that are dysregulated in patients with PTSD.

Physical exercise has beneficial effects for neural, cognitive, and inflammatory mechanisms linked to PTSD and is 
receiving growing attention as a viable intervention for reducing PTSD symptoms. In non-PTSD samples, for example, acute aerobic exercise drives increased prefrontal oxygenation (Endo et al., 2013) and frontal and hippocampal activation (Chen et al., 2019; Yanagisawa et al., 2010). These exerciseinduced changes, however, appear to be dependent on the intensity and duration of the exercise session (Fontes et al., 2018; Kao, Westfall, Soneson, Gurd, \& Hillman, 2017; Ligeza, Maciejczyk, Kalamala, Szygula, \& Wyczesany, 2018). Consistent with these neural changes, exercise can promote cognitive health as demonstrated by studies reporting improved cognitive function and neuroprotective effects following exercise regimes (Kirk-Sanchez \& McGough, 2014; Mandolesi et al., 2018). Studies on the effects of exercise on cognition show improvements in aspects of executive function, including working memory (Chen et al., 2019) and inhibitory control (Kao et al., 2017; Oberste et al., 2019), as well as learning and memory (Austin \& Loprinzi, 2019; Frith, Sng, \& Loprinizi, 2017). The benefits of exercise can additionally extend to exerting anti-inflammatory effects.

Studies looking into the effects of high-intensity interval training in populations with chronic inflammatory-related diseases show reductions in circulating proinflammatory cytokines, including TNF- $\alpha$ and IL-6 (Alizadeh et al., 2019; Gyorkos et al., 2019). Interestingly, IL-6 and IL-10 can be both increased following exercise and exert antiinflammatory effects through the inhibition of TNF- $\alpha$ and IL-1 $\beta$ (Pedersen, 2017). Although the underlying mechanisms in which exercise reduces inflammation are yet to be fully elucidated, findings suggest that it increases the production and release of anti-inflammatory cytokines reduces the expression of Toll-like receptors on monocytes and macrophages and reduces visceral fat mass (Collao, Rada, Francaux, Deldicque, \& Zbinden-Foncea, 2019; Gleeson et al., 2011).

Empirical demonstration of PTSD symptom reduction after resistance and aerobic exercise is evidenced by several clinical studies. Results from RCTs, including aerobic exercise or broadly exercise training in PTSD samples, have demonstrated clinically significant improvements in PTSD symptoms following exercise regimes (Fetzner \& Asmundson, 2015; Hall et al., 2019). Similarly, Whitworth, Nosrat, SantaBarbara, and Ciccolo (2019) tested the effects of a 3week, high-intensity resistance exercise intervention on PTSD symptoms and found large beneficial effects on symptoms of avoidance and hyperarousal. Notably, another study reported a nonsignificant trend on PTSD symptom reduction following an 8-week exercise- described as a combination of weight and endurance training - and sports intervention with male refugees (Knappe, Colledge, \& Gerber, 2019). Finally, a recent meta-analysis identified exercise as having positive effects on relevant aspects of PTSD, including exposure and desensitization to internal arousing cues, exercise-induced neuroplasticity, improved cognitive function, normalization of HPA function, and reductions in inflammatory markers (Hegberg, Hayes, \& Hayes, 2019). Together, these findings suggest that exercise promotes cognitive and antiinflammatory pathways, potentially resulting in improvements in PTSD symptoms, and thus, should be further developed as a novel treatment approach.

\section{Conclusions and future directions}

The mechanisms underpinning PTSD are complex. Nonetheless, accumulating evidence supports elevated inflammation and cognitive dysfunction as common features underlying this disorder. Biomarkers of inflammation, including proinflammatory cytokines, are consistently elevated in a significant proportion of patients with PTSD and thus may be driving PTSD symptoms. In addition, compelling evidence points to the detrimental effects of cognitive dysfunction on PTSD outcomes. In parallel with these findings, animal and human research demonstrate that PTSD, in the context of fear learning and extinction, is strongly linked to disrupted activity of brain networks that also support cognition. Translational work is beginning to elucidate how inflammation may impact these critical neural pathways in patients with PTSD, but the research remains limited. More evidence from human studies of PTSD is needed regarding how the interplay between inflammation and cognitive dysfunction contribute to PTSD trajectories. Given the consistent associations between inflammation and cognition, as well as the potential interaction of inflammation with critical neural pathways that support fear learning, extinction, and cognition, it is reasonable to hypothesize that these mechanisms in combination play a central role in PTSD.

The lines of evidence reviewed here for inflammatory, neurobiological, and cognitive interactions suggest avenues for more comprehensive measurement and integration of multiple systems into models of PTSD. Animal and human models should be leveraged to reveal the role of neuroinflammation in PTSD. Evidence is scarce regarding the neuroinflammatory processes involved in PTSD and how they contribute to the development, progression, and maintenance of the disorder. By addressing this gap, findings could provide direct evidence for the associations between inflammation, neurocircuitry, and PTSD to further identify central biomarkers that may facilitate diagnostic and intervention decision-making in PTSD. The study of brain microglia activation is a promising avenue to explore centrally the inflammatory activity and trajectories in patients with PTSD. Evidence demonstrates that increased cytokine production within the CNS results in higher microglia activation (Brown \& Vilalta, 2015). Interestingly, recent findings show microglia activation using PET in major depression (Holmes et al., 2018), another inflammatory disorder 
commonly comorbid with PTSD. Expanding the application of HRV measurement to neuroimaging research may help to shed light on the role of ANS dysregulation in neuroinflammation and PTSD. Notably, given that HRV is regulated by neural structures that also underpin cognitive-emotional processes, HRV measures in conjunction with neurocognitive testing and neuroimaging may provide a broader, integrative picture of cognitive and emotion regulation in PTSD. In general, more studies are needed that further examine explicitly and comprehensively cognitive function in PTSD. Utilization of standard and sensitive neurocognitive tests alongside physiological, neuroimaging, inflammation, and psychological markers will improve our growing understanding of the association between cognition and PTSD. Finally, further attention should be directed to better understand highly prevalent comorbidities in PTSD, including TBI. The mechanisms underlying PTSD and TBI comorbidity are not fully understood. More work is needed to elucidate the role of differences in TBI severity on PTSD symptom trajectories and inflammatory regulation. Considering the increased inflammatory response potentially ascribed to both conditions, their aggregated burden on neural and cognitive function can adversely affect emotional and behavioral regulation, as well as treatment and recovery. Thus, elucidating these integrative pathways in comorbid PTSD and TBI will have significant clinical implications. Given the devastating effects of PTSD on individuals, there is a critical need to better understand how inflammatory and cognitive regulatory systems together contribute to PTSD development, progression, and maintenance.

Considering that PTSD symptoms may persist in some patients following treatment with trauma-focused behavioral interventions or pharmacological approaches (Berger et al., 2010; Bradley et al., 2005; Schottenbauer et al., 2008; Steenkamp et al., 2015), it is likely that there are underlying mechanisms in PTSD that remain untargeted with the current interventions. The widespread effects of chronic elevated inflammation can have multiple repercussions in the CNS and therefore should not be the only targeted mechanism. Alternatively, targeting both inflammation and cognition, irrespective of whether inflammation leads to cognitive deficits or the inverse, may promote changes in the CNS that could lead to clinically meaningful improvements in PTSD symptoms. We speculate, based on the evidence, that the interventions described in this review could target both mechanisms in PTSD, and thus, deserve further research to test this assumption. Furthermore, there is considerable evidence showing the efficacy of these approaches in the treatment of neuropsychiatric conditions with altered inflammatory response and cognition (i.e., depression and Alzheimer's disease; Cavallo, Hunter, van der Hiele, \& Angilletta, 2016; Chiu et al., 2014; Hofmann \& Gomez, 2017; Lin et al., 2019; Motter et al., 2016).

\section{Conclusions}

The growing evidence for dysregulated inflammation and cognitive function in PTSD suggest that further research on the bidirectional interplay of these pathways will advance a deeper understanding of the etiology, progression, and maintenance of PTSD. In addition, elaborating on these underlying mechanisms can afford further development and testing of novel pharmacological approaches and behavioral interventions that effectively target inflammation and cognitive function and, in turn, meaningfully reduce PTSD symptomatology.

Author Notes The authors declare that they have no conflicts of interest. The authors report no financial or other relationship relevant to the subject of this article. This work was supported by the National Institute on Aging grant (R01AG049764) and a Research Supplements to Promote Diversity in Health-Related Research to the parent grant (R01AG049764-S1).

\section{References}

Aase, D. M., DiGangi, J. A., Babione, J. M., Schroth, C., Levy, D. M., Kennedy, A. E., ... Phan, K. L. (2017). PTSD symptoms are associated with visual retrieval performance in $\mathrm{OEF} / \mathrm{OIF} / \mathrm{OND}$ veterans. Psychiatry Research, 257, 156-162. https://doi.org/10.1016/j. psychres.2017.07.041

Acheson, D. T., Gresack, J. E., \& Risbrough, V. B. (2012). Hippocampal dysfunction effects on context memory: Possible etiology for posttraumatic stress disorder. Neuropharmacology, 62, 674-685. https:// doi.org/10.1016/j.neuropharm.2011.04.029

Akiki, T. J., Averill, C. L., Wrocklage, K. M., Schweinsburg, B., Scott, J. C., Martini, B., ... Abdallah, C. G. (2017). The association of PTSD symptom severity with localized hippocampus and amygdala abnormalities. Chronic Stress, 1, 1-10. https://doi.org/10.1177/ 2470547017724069

Alizadeh, A. M., Isanejad, A., Sadighi, S., Mardani, M., Kalaghchi, B., \& Hassan, Z. M. (2019). High-intensity interval training can modulate the systemic inflammation and HSP70 in the breast cancer: a randomized control trial. Journal of Cancer Research and Clinical Oncology, 145(10), 2583-2593. https://doi.org/10.1007/s00432019-02996-y

Alvarez, R., Biggs, A., Chen, G., Pine, D. S., \& Grillon, C. (2008). Contextual fear conditioning in humans cortical-hippocampal and amygdala contributions. Journal of Neuroinflammation, 28(24), 6211-6219.

American Psychiatry Association. (2013). Diagnostic and statistical manual of mental health disorders (5th ed.). Washington, DC: American Psychiatric Association.

Amodeo, G., Trusso, M. A., \& Fagiolini, A. (2017). Depression and inflammation: Disentangling a clear yet complex and multifaceted link. Neuropsychiatry, 7(4), 448-457. https://doi.org/10.4172/ Neuropsychiatry. 1000236

Apfel, B. A., Ross, J., Hlavin, J., Meyerhoff, D. J., Metzler, T. J., Marmar, C. R., ... Neylan, T. C. (2011). Hippocampal volume differences in Gulf War veterans with current versus lifetime posttraumatic stress disorder symptoms. Biological Psychiatry, 69(6), 541-548. https:// doi.org/10.1016/j.biopsych.2010.09.044

Ashley, V., Honzel, N., Larsen, J., Justus, T., \& Swick, D. (2013). Attentional bias for trauma-related words: Exaggerated emotional Stroop effect in Afghanistan and Iraq war veterans with PTSD. BMC Psychiatry, 13, 86. 
Aupperle, R. L., Melrose, A. J., Stein, M. B., \& Paulus, M. P. (2012). Executive function and PTSD: Disengaging from trauma. Neuropharmacology, 62(2), 686-694. https://doi.org/10.1016/j. neuropharm.2011.02.008

Austin, M., \& Loprinzi, P. D. (2019). Acute exercise and mindfulness meditation on learning and memory: Randomized controlled intervention. Health Promotion Perspective, 9(4), 314-318. https://doi. org/10.15171/hpp.2019.43

Awad, W., Ferreira, G., \& Maroun, M. (2015). Dissociation of the role of infralimbic cortex in learning and consolidation of extinction of recent and remote aversion memory. Neuropsychopharmacology, 40(11), 2566-2575. https://doi.org/10.1038/npp.2015.103

Baeuchl, C., Meyer, P., Hoppstadter, M., Diener, C., \& Flor, H. (2015). Contextual fear conditioning in humans using feature-identical contexts. Neurobiology of Learning and Memory, 121, 1-11. https://doi. org/10.1016/j.nlm.2015.03.001

Bandelow, B., Baldwin, D., Abelli, M., Bolea-Alamanac, B., Bourin, M., Chamberlain, S. R., ... Riederer, P. (2017) Biological markers for anxiety disorders, OCD and PTSD: A consensus statement. Part II: Neurochemistry, neurophysiology and neurocognition. The World Journal of Biological Psychiatry, 18(3), 162-214. https://doi.org/ 10.1080/15622975.2016.1190867

Barlow, D., Lehrer, P. M., Woolfolk, R. L., \& Sime, W. E. (2007). Principles and practice of stress management (3 ed.). New York: The Guildfor Press.

Baumeister, D., Akhtar, R., Ciufolini, S., Pariante, C. M., \& Mondelli, V. (2016). Childhood trauma and adulthood inflammation: A metaanalysis of peripheral C-reactive protein, interleukin-6 and tumour necrosis factor-alpha. Molecular Psychiatry, 21(5), 642-649. https:// doi.org/10.1038/mp.2015.67

Baune, B. T., Malhi, G. S., Morris, G., Outhred, T., Hamilton, A., Das, P., ... Singh, A. B. (2018). Cognition in depression: Can we THINC-it better? Journal of Affective Disorders, 225, 559-562. https://doi.org/ 10.1016/j.jad.2017.08.080

Beauchaine, T., Gatzke-Kopp, L., \& Mead, H. 2007. Polyvagal Theory and developmental psychopathology emotion dysregulation and conduct problems from preschool to adolescence. Biological Psychology, 74(2), 174-184.

Beblo, T., Sinnamon, G., \& Baune, B. T. (2011). Specifying the neuropsychology of affective disorders: Clinical, demographic and neurobiological factors. Neuropsychology Review, 21(4), 337-359. https://doi.org/10.1007/s11065-011-9171-0

Benigni, A., Cassis, P., \& Remuzzi, G. (2010). Angiotensin II revisited: New roles in inflammation, immunology and aging. EMBO Molecular Medicine, 2(7), 247-257. https://doi.org/10.1002/ emmm.201000080

Ben-Zion, Z., Fine, N. B., Keynan, N. J., Admon, R., Green, N., Halevi, M., ... Shalev, A. Y. (2018). Cognitive flexibility predicts PTSD symptoms: Observational and interventional studies. Frontiers in Psychiatry, 9, 477. https://doi.org/10.3389/fpsyt.2018.00477

Bergen-Cico, D., Possemato, K., \& Pigeon, W. (2014). Reductions in cortisol associated with primary care brief mindfulness program for veterans with PTSD. Medical Care, 52(S25-S31).

Berger, W., Mendlowicz, M. V., Marques-Portella, C., Kinrys, G., Fontenelle, L. F., Marmar, C. R., \& Figueira, I. (2010). Pharmacologic alternatives to antidepressants in posttraumatic stress disorder: A systematic review. Progress in NeuroPsychopharmacology \& Biological Psychiatry, 33(2), 169-180. https://doi.org/10.1016/j.pnpbp

Beydoun, M. A., Weiss, J., Obhi, H. K., Beydoun, H. A., Dore, G. A., Liang, H., ... Zonderman, A. B. (2019). Cytokines are associated with longitudinal changes in cognitive performance among urban adults. Brain, Behavior, and Immunity. https://doi.org/10.1016/j.bbi. 2019.04.027

Bisson, J. I., Roberts, N. P., Andrew, M., Cooper, R., \& Lewis, C. (2013). Psychological therapies for chronic post-traumatic stress disorder
(PTSD) in adults. Cochrane database of systematic reviews $(1,60$. 2).

Black, D. S., \& Slavich, G. M. (2016). Mindfulness meditation and the immune system: A systematic review of randomized controlled trials. Annals of the New York Academy of Sciences, 1373(1), 13-24. https://doi.org/10.1111/nyas.12998

Blanchette, I., Rutembesa, E., Habimana, E., \& Caparos, S. (2019). Longterm cognitive correlates of exposure to trauma: Evidence from Rwanda. Psychological Trauma, 11(2), 147-155. https://doi.org/ $10.1037 / \operatorname{tra} 0000388$

Bloodgood, D. W., Sugam, J. A., Holems, A., \& Kash, T. L. (2018). Fear extinction requires infralimbic cortex projections to the basolateral amygdala. Translational Psychiatry, 8, 60. https://doi.org/10.1038/ s41398-018-0106-x

Bomyea, J., Stein, M. B., \& Lang, A. J. (2015). Interference control training for PTSD: A randomized controlled trial of a novel computer-based intervention. Journal of Anxiety Disorders, 34, 33-42. https://doi.org/10.1016/j.janxdis.2015.05.010

Bonaz, B., Sinniger, V., \& Pellissier, S. (2016). Anti-inflammatory properties of the vagus nerve: Potential therapeutic implications of vagus nerve stimulation. The Journal of Physiology, 594(20), 5781-5790. https://doi.org/10.1113/JP271539

Bonne, O., Vythilingam, M., Inagaki, M., Wood, S., Neumeister, A., Nugent, A. C., ... Charney, D. S. (2008). Reduced posterior hippocampal volume in posttraumatic stress. The Journal of Clinical Psychiatry, 69(7), 1087-1091.

Bortolato, B., Carvalho, A., \& McIntyre, R. (2015). Cognitive dysfunction in major depressive disorder: A state-of-the-art clinical review. CNS \& Neurological Disorders - Drug Targets, 13(10), 1804-1818. https://doi.org/10.2174/1871527313666141130203823

Bradley, R., Greene, J., Russ, E., Dutra, L., \& Westen, D. (2005). A multidimensional meta-analysis of psychotherapy for PTSD. American Journal of Psychiatry, 162(2), 214-227. https://doi.org/ 10.1176/appi.ajp.162.2.214

Brandes, D., Ben-Schachar, G., Gilboa, A., Bonne, O., Freedman, S., \& Shalev, A. Y. (2002). PTSD symptoms and cognitive performance in recent trauma survivors. Psychiatry Research, 110, 231-238.

Bremner, J. D., Elzinga, B., Schmahl, C., \& Vermetten, E. (2007). Structural and functional plasticity of the human brain in posttraumatic stress disorder. In Stress Hormones and Post Traumatic Stress Disorder Basic Studies and Clinical Perspectives (pp. 171-186).

Bremner, J. D., Vermetten, E., Afzal, N., \& Vythilingam, M. (2004). Deficits in verbal declarative memory function in women with childhood sexual abuse-related posttraumatic stress disorder. The Journal of Nervous and Mental Disease, 192(10), 643-649. https://doi.org/ 10.1097/01.nmd.0000142027.52893.c8

Bremner, J. D., Vermetten, E., Schmahl, C., Vaccarino, V., Vythilingam, M., Afzal, N., ... Charney, D. S. (2005). Positron emission tomographic imaging of neural correlates of a fear acquisition and extinction paradigm in women with childhood sexual-abuse-related posttraumatic stress disorder. Psychological Medicine, 35(6), 791-806.

Brewin, C. R., Kleiner, J. S., Vasterling, J. J., \& Field, A. P. (2007). Memory for emotionally neutral information in posttraumatic stress disorder: A meta-analytic investigation. Journal of Abnormal Psychology, 116(3), 448-463. https://doi.org/10.1037/0021-843X. 116.3.448

Bromis, K., Calem, M., Reinders, A. A. T. S., Williams, S. C. R., \& Kempton, M. J. (2018). Meta-analysis of 89 structural MRI studies in posttraumatic stress disorder and comparison with major depressive disorder. The American Journal of Psychiatry, 175, 989-998. https://doi.org/10.1176/appi.ajp.2018.17111199

Brown, G. C., \& Vilalta, A. (2015). How microglia kill neurons. Brain Research, 1628, 288-297. https://doi.org/10.1016/j.brainres.2015. 08.031

Brown, V. M., LaBar, K. S., Haswell, C. C., Gold, A. L., Mid-Atlantic MIRECC Workgroup, McCarthy, G., \& Morey, R. A. (2014). 
Altered resting-state functional connectivity of basolateral and centromedial amygdala complexes in posttraumatic stress disorder. Neuropsychopharmacology, 39, 351-359. https://doi.org/10.1038/ npp.2013.197

Brownlow, J. A., Brown, T. S., \& Mellman, T. A. (2014). Relationships of posttraumatic stress symptoms and sleep measures to cognitive performance in young-adult African Americans. Journal of Traumatic Stress, 27(2), 217-223. https://doi.org/10.1002/jts.21906

Bryant, R. A., Felmingham, K. L., Kemp, A. H., Barton, M., Peduto, A. S., Rennie, C., ... Williams, L. M. (2005). Neural networks of information processing in posttraumatic stress disorder: A functional magnetic resonance imaging study. Biological Psychiatry, 58(2), 111-118. https://doi.org/10.1016/j.biopsych.2005.03.021

Burriss, L., Ayers, E., Ginsberg, J., \& Powell, D. A. (2008). Learning and memory impairment in PTSD: Relationship to depression. Depression and Anxiety, 25(2), 149-157. https://doi.org/10.1002/ da.20291

Calabrese, F., Rossetti, A. C., Racagni, G., Gass, P., Riva, M. A., \& Molteni, R. (2014). Brain-derived neurotrophic factor: A bridge between inflammation and neuroplasticity. Frontiers in Cellular Neuroscience, 8, 430. https://doi.org/10.3389/fncel.2014.00430

Campbell, T. A., Nelson, L. A., Lumpkin, R., Yoash-Gantz, R. E., Pickett, T. C., \& McCormick, C. L. (2009). Neuropsychological measures of processing speed and executive functioning in combat veterans with PTSD, TBI, and comorbid TBI/PTSD. Psychiatric Annals, 39(8), 796-803. https://doi.org/10.3928/00485713-20090728-01

Capuron, L., Pagnoni, G., Demetrashvili, M., Woolwine, B. J., Nemeroff, C. B., Berns, G. S., \& Miller, A. H. (2005). Anterior cingulate activation and error processing during interferon-alpha treatment. Biological Psychiatry, 58(3), 190-196.

Casada, J. H., \& Roache, J. D. (2005). Behavioral Inhibition and Activation in Posttraumatic Stress Disorder. The Journal of Nervous and Mental Disease, 193(2), 102-109. https://doi.org/10. 1097/01.nmd.0000152809.20938.37

Cavallo, M., Hunter, E. M., van der Hiele, K., \& Angilletta, C. (2016). Computerized structured cognitive training in patients affected by early-stage Alzheimer's disease is feasible and effective: A randomized controlled study. Archives of Clinical Neuropsychology. https:// doi.org/10.1093/arclin/acw072

Chaaya, N., Battle, A. R., \& Johnson, L. R. (2018). An update on contextual fear memory mechanisms: Transition between amygdala and hippocampus. Neuroscience and Biobehavioral Reviews, 92, 43-54. https://doi.org/10.1016/j.neubiorev.2018.05.013

Chang, Y., \& Wei, W. (2015). Angiotensin II in inflammation, immunity and rheumatoid arthritis. Clinical and Experimental Immunology, 179(2), 137-145. https://doi.org/10.1111/cei.12467

Charlton, R. A., Lamar, M., Zhang, A., Ren, X., Ajilore, O., Pandey, G. N., \& Kumar, A. (2018). Associations between pro-inflammatory cytokines, learning, and memory in late-life depression and healthy aging. International Journal of Geriatric Psychiatry, 33(1), 104 112. https://doi.org/10.1002/gps.4686

Chen, F., Chen, Y., Schneider, S., Kao, S., Huang, C., \& Chang, Y. (2019). Effects of exercise modes on neural processing of working memory in late middle-aged adults: An fMRI study. Frontiers in Aging Neuroscience, 11, 224. https://doi.org/10.3389/fnagi.2019. 00224

Chesnokova, V., Pechnick, R. N., \& Wawrowsky, K. (2016). Chronic peripheral inflammation, hippocampal neurogenesis, and behavior. Brain, Behavior, and Immunity, 58, 1-8.

Chiu, W. C., Ho, W. C., Lin, M. H., Lee, H. H., Yeh, Y. C., Wang, J. D., ... Health Data Analysis in Taiwan Research, G. (2014). Angiotension receptor blockers reduce the risk of dementia. Journal of Hypertension, 32(4), 938-947. https://doi.org/10.1097/HJH. 0000000000000086

Ciocchi, S., Herry, C., Grenier, F., Wolff, S. B. E., Letzkus, J. J., Vlachos, I. ... Luthi, A. (2010). Encoding of conditioned fear in central amygdala inhibitory circuits. Nature, 468, 277-282. https://doi. org/10.1038/nature09559

Cisler, J. M., James, G. A., Tripathi, S., Mletzko, T., Heim, C., Hu, X. P., ... Kilts, C. D. (2013). Differential functional connectivity within an emotion regulation neural network among individuals resilient and susceptible to the depressogenic effects of early life stress. Psychological Medicine, 43(3), 507-518. https://doi.org/10.1017/ S0033291712001390

Clausen, A. N., Francisco, A. J., Thelen, J., Bruce, J., Martin, L., McDowd, J., ... Aupperle, R. L. (2017). PTSD and cognitive symptoms relate to inhibition-related prefrontal activation and functional connectivity. Depression and Anxiety, 34(5), 427-436. https://doi. org/10.1002/da.22613

Cohen, B. E., Neylan, T. C., Yaffe, K., Samuelson, K. W., Li, Y., \& Barnes, D. E. (2013). Posttraumatic stress disorder and cognitive function: Findings from the mind your heart study. The Journal of Clinical Psychiatry, 74(11), 1063-1070. https://doi.org/10.4088/ JCP. $12 \mathrm{~m} 08291$

Collao, N., Rada, I., Francaux, M., Deldicque, L., \& Zbinden-Foncea, H. (2019). Anti-Inflammatory Effect of Exercise Mediated by TollLike Receptor Regulation in Innate Immune Cells - A Review. International Reviews of Immunology, 4, 1-14. https://doi.org/10. 1080/08830185.2019.1682569

Combs, H. L., Berry, D. T. R., Pape, T., Babcock-Parziale, J., Smith, B., Schleenbaker, R., ... High, W. M. Jr. (2015). The effects of mild traumatic brain injury, post-traumatic stress disorder, and combined mild traumatic brain injury/post-traumatic stress disorder on returning veterans. Journal of Neurotrauma, 32(13), 956-966. https://doi.org/10.1089/neu.2014.3585.

Contractor, A. A., Elhai, J. D., Ractliffe, K. C., \& Forbes, D. (2013). PTSD's underlying symptom dimensions and relations with behavioral inhibition and activation. Journal of Anxiety Disorders, 27(7), 645-651. https://doi.org/10.1016/j.janxdis.2013.07.007

Corcoran, K. A., \& Maren, S. (2001). Hippocampal inactivation disrupts contextual retrieval of fear memory after extinction. The Journal of Neuroscience, 21(5), 1720-1726.

Coutinho, A. E., \& Chapman, K. E. (2011). The anti-inflamatory and immunosuppressive effects of glucocorticoids, recent developments and mechanistics insights. Molecular and Cellular Endocrinology, 335(1), 2-13. https://doi.org/10.1016/j.mce.2010.04.005

Creswell, J. D., Taren, A. A., Lindsay, E. K., Greco, C. M., Gianaros, P. J., Fairgrieve, A., ... Ferris, J. L. (2016). Alterations in resting-state functional connectivity link mindfulness meditation with reduced interleukin-6: A randomized controlled trial. Biological Psychiatry, 80(1), 53-61. https://doi.org/10.1016/j.biopsych.2016.01.008

Critchely, H. D., Mathias, C. J., \& Dolan, R. J. (2002). Fear conditioning in humans the influence of awareness and autonomic arousal on functional neuroanatomy. Neuron, 33, 653-663.

Crowell, T. A., Kieffer, K. M., Siders, C. A., \& Vanderploeg, R. D. (2002). Neuropsychological findings in combat-related posttraumatic stress disorder. The Clinical Neuropsychologist, 16(3), 310-321. https://doi.org/10.1076/clin.16.3.310.13851

Dalgleish, T., Rolfe, J., Golden, A. M., Dunn, B. D., \& Barnard, P. J. (2008). Reduced autobiographical memory specificity and posttraumatic stress: Exploring the contributions of impaired executive control and affect regulation. Journal of Abnormal Psychology, 117(1), 236-241. https://doi.org/10.1037/0021-843X.117.1.236

Danese, A., \& Lewis, S. J. (2017). Psychoneuroimmunology of early-life stress: The hidden wounds of childhood trauma? Neuropsychopharmacology, 42(1), 99-114. https://doi.org/10. 1038/npp.2016.198

Dantzer, R., O'Connor, J. C., Freund, G. G., Johnson, R. W., \& Kelley, K. W. (2008). From inflammation to sickness and depression: When the immune system subjugates the brain. Nature Reviews. Neuroscience, 9(1), 46-56. https://doi.org/10.1038/nrn2297 
Daskalakis, N. P., Cohen, H., Nievergelt, C. M., Baker, D. G., Buxbaum, J. D., Russo, S. J., \& Yehuda, R. (2016). New translational perspectives for blood-based biomarkers of PTSD: From glucocorticoid to immune mediators of stress susceptibility. Experimental Neurology, 284(PtB), 133-140. https://doi.org/10.1016/j.expneurol.2016.07. 024

Davis, L. L., Whetsell, C., Hamner, M. B., Carmody, J., Rothbaum, B. O., Allen, R. S., ... Bremner, J. D. (2018). A multisite randomized controlled trial of mindfulness-based stress reduction in the treatment of posttraumatic stress disorder. Psychiatric Research and Clinical Practice. https://doi.org/10.1176/appi.prcp.20180002

Davis, P., Zaki, Y., Maguire, J., \& Reijmers, L. G. (2017). Cellular and oscillatory substrates of fear extinction learning. Nature Neuroscience, 20(11), 1624-1633. https://doi.org/10.1038/nn.4651

DeGutis, J., Esterman, M., McCulloch, B., Rosenblatt, A., Milberg, W., \& McGlinchey, R. (2015). Posttraumatic psychological symptoms are associated with reduced inhibitory control, not general executive dysfunction. Journal of the International Neuropsychological Society, 21(5), 342-352. https://doi.org/10.1017/ S1355617715000235

Delpech, J. C., Wei, L., Hao, J., Yu, X., Madore, C., Butovsky, O., \& Kaffman, A. (2016). Early life stress perturbs the maturation of microglia in the developing hippocampus. Brain, Behavior, and Immunity, 57, 79-93. https://doi.org/10.1016/j.bbi.2016.06.006

Dennis, P. A., Watkins, L. L., Calhoun, P. S., Oddone, A., Sherwood, A., Dennis, M. F., ... Beckham, J. C. (2014). Posttraumatic stress, heart rate variability, and the mediating role of behavioral health risks. Psychosomatic Medicine, 76(8), 629-637. https://doi.org/10.1097/ PSY.0000000000000110

DePrince, A. P., \& Freyd, J. J. (2004). Forgetting trauma stimuli. Psychological Science, 15(7), 488-492. https://doi.org/10.1111/j. 0956-7976.2004.00706.x

Desrosiers, A., Vine, V., Klemanski, D. H., \& Nolen-Hoeksema, S. (2013). Mindfulness and emotion regulation in depression and anxiety: Common and distinct mechanisms of action. Depression and Anxiety, 30(7), 654-661. https://doi.org/10.1002/da.22124

Devoto, C., Arcurio, L., Fetta, J., Ley, M., Rodney, T., Kanefsky, R., \& Gill, J. (2017). Inflammation relates to chronic behavioral and neurological symtpoms in military personnel with traumatic brain injuries. Cell Transplantation, 26(7), 1169-1177. https://doi.org/10. 1177/0963689717714098

Diamond, D. M., Fleshner, M., Ingersoll, N., \& Rose, G. (1996). Psychological stress impairs spatial working memory: Relevance to electrophysiological studies of hippocampal function. Behavioral Neuroscience, 110(4), 661-672. https://doi.org/10. 1037/0735-7044.110.4.661

DiGangi, J. A., Gomez, D., Mendoza, L., Jason, L. A., Keys, C. B., \& Koenen, K. C. (2013). Pretrauma risk factors for posttraumatic stress disorder: A systematic review of the literature. Clinical Psychology Review, 33(6), 728-744. https://doi.org/10.1016/j.cpr.2013.05.002

Doenni, V. M., Song, C. M., Hill, M. N., \& Pittman, Q. J. (2017). Earlylife inflammation with LPS delays fear extinction in adult rodents. Brain, Behavior, and Immunity, 63, 176-185. https://doi.org/10. 1016/j.bbi.2016.11.022

Donzis, E. J., \& Tronson, N. C. (2014). Modulation of learning and memory by cytokines: signaling mechanisms and long term consequences. Neurobiology of Learning and Memory, 115, 68-77. https://doi.org/10.1016/j.nlm.2014.08.008

Dunlop, B. W., \& Wong, A. (2019). The hypothalamic-pituitary-adrenal axis in PTSD: Pathophysiology and treatment interventions. Progress in Neuro-Psychopharmacology \& Biological Psychiatry, 89, 361-379. https://doi.org/10.1016/j.pnpbp.2018.10.010

Dutra, S. J., Marx, B. P., McGlinchey, R., DeGutis, J., \& Esterman, M. (2018). Reward ameliorates posttraumatic stress disorder-related impairment in sustained attention. Chronic Stress (Thousand Oaks), 2. https://doi.org/10.1177/2470547018812400
Duvarci, S., Popa, D., \& Paré, D. (2011). Central amygdala activity during fear conditioning. Journal of Neuroscience, 31(1), 289-294. https://doi.org/10.1523/JNEUROSCI.4985-10.2011.

Eisenberger, N., Lieberman, M. D., \& Satpute, A. B. (2005). Personality from a controlled processing perspective: An fMRI study of neuroticism, extraversion, and self-consciousness. Cognitive, Affective, \& Behavioral Neuroscience, 5(2), 169-181. https://doi.org/10.3758/ CABN.5.2.169

Elrich, J. C., Bush, D. E. A., LeDoux, J. E. (2012). The role of the lateral amygdala in the retrieval and maintenance of fear-memories formed by repeated probabilistic reinforcement. Frontiers in Behavioral Neuroscience, 6, 16. https://doi.org/10.3389/fnbeh.2012.00016

Endo, K., Matsukawa, K., Liang, N., Nakatsuka, C., Tsuchimochi, H., Okamura, H., \& Hamaoka, T. (2013). Dynamic exercise improves cognitive function in association with increased prefrontal oxygenation. The Journal of Physiological Sciences, 63(4), 287-298. https://doi.org/10.1007/s12576-013-0267-6

Eren-Kocak, E., Kilic, C., Aydin, I., \& Hizli, F. G. (2009). Memory and prefrontal functions in earthquake survivors: differences between current and past post-traumatic stress disorder patients. Acta Psychiatrica Scandinavica, 119(1), 35-44. https://doi.org/10.1111/ j.1600-0447.2008.01281.x

Esterman, M., DeGutis, J., Mercado, R., Rosenblatt, A., Vasterling, J. J., Milberg, W., \& McGlinchey, R. (2013). Stress-related psychological symptoms are associated with increased attentional capture by visually salient distractors. Journal of the International Neuropsychological Society, 19(7), 835-840. https://doi.org/10. 1017/S135561771300057X

Fabio, R. A., \& Towey, G. E. (2018). Long-term meditation: The relationship between cognitive processes, thinking styles and mindfulness. Cognitive Processing, 19(1), 73-85. https://doi.org/10.1007/ s10339-017-0844-3

Falconer, E., Allen, A., Felmingham, K. L., Williams, L. M., \& Bryant, R. A. (2013). Inhibitory neural activity predicts response to cognitivebehavioral therapy for posttraumatic stress disorder. The Journal of Clinical Psychiatry, 74(9), 895-901. https://doi.org/10.4088/JCP. $12 \mathrm{~m} 08020$

Fani, N., Jovanovic, T., Ely, T. D., Bradley, B., Gutman, D., Tone, E. B., \& Ressler, K. J. (2012). Neural correlates of attention bias to threat in post-traumatic stress disorder. Biological Psychology, 90(2), 134 142. https://doi.org/10.1016/j.biopsycho.2012.03.001

Fanselow, M. S. (2010). From contextual fear to a dynamic view of memory systems. Trends in Cognitive Sciences, 14(1), 7-15. https://doi.org/10.1016/j.tics.2009.10.008

Felger, J. C. (2018). Imaging the role of inflammation in mood and anxiety-related disorders. Current Neuropharmacology, 16(5), 533-558. https://doi.org/10.2174/1570159X15666171123201142

Fetzner, M. G., \& Asmundson, G. J. (2015). Aerobic exercise reduces symptoms of posttraumatic stress disorder: A randomized controlled trial. Cognitive Behaviour Therapy, 44(4), 301-313.

Flor, H., \& Wessa, M. (2010). Memory and posttraumatic stress disorder: A matter of context?. Zeitschrift für Psychologie/Journal of Psychology, 218(2), 61-63. https://doi.org/10.1027/0044-3409/ a000012

Fontes, E., Bortolotti, H., Grandejean da Costa, K., Machado de Campos, B., Castanho, G. K., Hohl, R., .. Min, L. L. (2018). Modulation of cortical and subcortical brain areas at low and high exercise intensities. British Journal of Sports Medicine, 0, 1-7. https://doi.org/10. 1136/bjsports-2018-100295

Friedman, B. H. (2007). An autonomic flexibility-neurovisceral integration model of anxiety and cardiac vagal tone. Biological Psychology, 74(2), 185-199. https://doi.org/10.1016/j.biopsycho.2005.08.009

Frith, E., Sng, E., \& Loprinizi, P. D. (2017). Randomized controlled trial evaluating the temporal effects of high-intensity exercise on learning, short-term and long-term memory, and prospective memory. 
The European Journal of Neuroscience, 46(10), 2557-2564. https:// doi.org/10.1111/ejn.13719

Galecki, P., Mossakowska-Wojcik, J., \& Talarowska, M. (2018). The anti-inflammatory mechanism of antidepressants - SSRIs, SNRIs. Progress in Neuro-Psychopharmacology \& Biological Psychiatry, 80(Pt C), 291-294. https://doi.org/10.1016/j.pnpbp.2017.03.016

Gallegos, A. M., Crean, H. F., Pigeon, W. R., \& Heffner, K. L. (2017). Meditation and yoga for posttraumatic stress disorder: A metaanalytic review of randomized controlled trials. Clinical Psychology Review, 58, 115-124. https://doi.org/10.1016/j.cpr. 2017.10.004

Garcia, R., Spennato, G., Nilsson-Todd, L., Moreau, J. L., \& Deschaux, O. (2008). Hippocampal low-frequency stimulation and chronic mild stress similarly disrupt fear extinction memory in rats. Neurobiology of Learning and Memory, 89(4), 560-566. https:// doi.org/10.1016/j.nlm.2007.10.005

Garfinkel, S. N., Abelson, J. L., King, A. P., Sripada, R. K., Wang, X., Gaines, L. M., \& Liberzon, I. (2014). Impaired contextual modulation of memories in PTSD: An fMRI and psychophysiological study of extinction retention and fear renewal. The Journal of Neuroscience, 34(40), 13435-13443. https://doi.org/10.1523/ JNEUROSCI.4287-13.2014

Gerritsen, R. J. S., \& Band, G. P. H. (2018). Breath of life: The respiratory vagal stimulation model of contemplative activity. Frontiers in Human Neuroscience, 12, 397. https://doi.org/10.3389/fnhum. 2018.00397

Gevirtz, R. (2013). The Promise of Heart Rate Variability Biofeedback: Evidence-Based Applications. Biofeedback, 41(3), 110-120. https:// doi.org/10.5298/1081-5937-41.3.01

Gilbertson, M. W., Gurvits, T. V., Lasko, N. B., Orr, S. P., \& Pitman, R. K. (2001). Multivariate assessment of explicit memory function in combat veterans with posttraumatic stress disorder. Journal of Traumatic Stress, 14(2), 413-432. https://doi.org/10.1023/A: 1011181305501

Gill, J., Luckenbaugh, D., Charney, D., \& Vythilingam, M. (2010). Sustained elevation of serum interleukin-6 and relative insensitivity to hydrocortisone differentiates posttraumatic stress disorder with and without depression. Biological Psychiatry, 68(11), 999-1006. https://doi.org/10.1016/j.biopsych.2010.07.033

Gillie, B. L., \& Thayer, J. F. (2014). Individual differences in resting heart rate variability and cognitive control in posttraumatic stress disorder. Frontiers in Psychology, 5, 758. https://doi.org/10.3389/fpsyg.2014. 00758

Giuliani, N. R., Drabant, E. M., \& Gross, J. J. (2011). Anterior cingulate cortex volume and emotion regulation: Is bigger better? Biological Psychology, 86(3), 379-382. https://doi.org/10.1016/j.biopsycho. 2010.11.010

Giustino, T. \& Maren, S. (2015). The role of the medial prefrontal cortex in the conditioning and extinction of fear. Frontiers in Behavioral Neuroscience, 9, 298. https://doi.org/10.3389/fnbeh.2015.00298

Gleeson, M. Bishop, N. C., Stensel, D. J., Lindley, M. R., Mastana, S. S., \& Nimmo, M. A. (2011). The anti-inflammatory effects of exercise: Mechanisms and implications for the prevention and treatment of disease. Nature Reviews. Immunology, 11(9), 607-615. https://doi. org/10.1038/nri3041

Godsil, B. P., Kiss, J. P., Spedding, M., \& Jay, T. M. (2013). The hippocampal-prefrontal pathway: the weak link in psychiatric disorders? European Neuropsychopharmacology, 23(10), 1165-1181. https://doi.org/10.1016/j.euroneuro.2012.10.018

Goessl, V. C., Curtiss, J. E., \& Hofmann, S. G. (2017). The effect of heart rate variability biofeedback training on stress and anxiety: A metaanalysis. Psychological Medicine, 47(15), 2578-2586. https://doi. org/10.1017/S0033291717001003

Goldin, P. R., \& Gross, J. J. (2010). Effects of mindfulness-based stress reduction (MBSR) on emotion regulation in social anxiety disorder. Emotion, 10(1), 83. https://doi.org/10.1037/a0018441
Golier, J., \& Yehuda, R. (2002). Neuropsychological processes in posttraumatic stress disorder. Psychiatric Clinics of North America, 25, 295-315.

Golier, J. A., Harvey, P. D., Legge, J., \& Yehuda, R. (2006). Memory performance in older trauma survivors: implications for the longitudinal course of PTSD. Annals of the New York Academy of Sciences, 1071, 54-66. https://doi.org/10.1196/annals.1364.006

Gross, J. J. (2002). Emotion regulation: Affective, cognitive, and social consequences. Psychophysiology, 39, 281-291. https://doi.org/10. 1017/S0048577201393198

Gruol, D. L. (2015). IL-6 regulation of synaptic function in the CNS. Neuropharmacology, 96(Pt A), 42-54. https://doi.org/10.1016/j. neuropharm.2014.10.023

Gyorkos, A., Baker, M., Miutz, L. N., Lown, D. A., Jones, M., HoughtonRahrig, L. D. (2019). Carbohydrate-restricted diet and high-intensity interval training exercise improve cardio-metabolic and inflammatory profiles in metabolic syndrome: A randomized crossover trial. Cureus, 11(9), e5596. https://doi.org/10.7759/cureus.5596

Hall, K. S., Morey, M. C., Bosworth, H. B., Beckham, J. C., Pebole, M. M., Sloane, R. \& Pieper, C. F. (2019). Pilot randomized controlled trial of exercise training for older veterans with PTSD. Journal of Behavioral Medicine. Advance online publication. https://doi.org/ 10.1007/s10865-019-00073-w

Harrison, N. A., Brydon, L., Walker, C., Gray, M. A., Steptoe, A., \& Critchley, H. D. (2009a). Inflammation causes mood changes through alterations in subgenual cingulate activity and mesolimbic connectivity. Biological Psychiatry, 66(5), 407-414. https://doi.org/ 10.1016/j.biopsych.2009.03.015

Harrison, N. A., Brydon, L., Walker, C., Gray, M. A., Steptoe, A., Dolan, R. J., \& Critchley, H. D. (2009b). Neural origins of human sickness in interoceptive responses to inflammation. Biological Psychiatry, 66(5), 415-422. https://doi.org/10.1016/j.biopsych.2009.03.007

Harrison, N. A., Doeller, C. F., Voon, V., Burgess, N., \& Critchley, H. D. (2014). Peripheral inflammation acutely impairs human spatial memory via actions on medial temporal lobe glucose metabolism. Biological Psychiatry, 76(7), 585-593. https://doi.org/10.1016/j. biopsych.2014.01.005

Hart, J., Jr., Kimbrell, T., Fauver, P., Cherry, B. J., Pitcock, J., Booe, L. Q., ... Freeman, T. W. (2008). Cognitive dysfunctions associated with PTSD: Evidence from World War II prisoners of war. The Journal of Neuropsychiatry and Clinical Neurosciences, 20(3), 309-316. https://doi.org/10.1176/appi.neuropsych.20.3.30910.1176/jnp. 2008.20.3.309

Hayes, J., Hayes, S. M., \& Mikedis, A. M. (2012). Quantitative metaanalysis of neural activity in posttraumatic stress disorder. Biology of Mood \& Anxiety Disorders, 9, 1-13. https://doi.org/10.1186/20455380-2-9

Hayes, J. P., Vanelzakker, M. B., \& Shin, L. M. (2012). Emotion and cognition interactions in PTSD: A review of neurocognitive and neuroimaging studies. Frontiers in Integrative Neuroscience, 6 , 89. https://doi.org/10.3389/fnint.2012.00089

Heffner, K. L., Crean, H. F., \& Kemp, J. E. (2016). Meditation programs for veterans with posttraumatic stress disorder: Aggregate findings from a multi-site evaluation. Psychological Trauma, 8(3), 365-374. https://doi.org/10.1037/tra0000106

Hegberg, N. J., Hayes, J. P., \& Hayes, S. M. (2019). Exercise Intervention in PTSD: A Narrative Review and Rationale for Implementation. Frontiers in Psychiatry, 10, 133. https://doi.org/10.3389/fpsyt.2019. 00133

Hermans, E. J., Battaglia, F. P., Atsak, P., de Voogd, L. D., Fernandez, G., \& Roozendaal, B. (2014). How the amygdala affects emotional memory by altering brain network properties. Neurobiology of Learning and Memory, 112, 2-16. https://doi.org/10.1016/j.nlm. 2014.02.005

Herry, C., Ferraguti, F., Singewald, N., Letzkus, J. J., Ehrlich, I., \& Luthi, A. (2010). Neuronal circuits of fear extinction. The European 
Journal of Neuroscience, 31(4), 599-612. https://doi.org/10.1111/j. 1460-9568.2010.07101.x

Hofmann, S. G. (2008). Cognitive processes during fear acquisition and extinction in animals and humans: Implications for exposure therapy of anxiety disorders. Clinical Psychology Review, 28(2), 199-210.

Hofmann, S. G., \& Gomez, A. F. (2017). Mindfulness-based interventions for anxiety and depression. The Psychiatric Clinics of North America, 40(4), 739-749. https://doi.org/10.1016/j.psc.2017.08.008

Hofmann, S. G., Quaglia, J. T., Zeidan, F., Grossenbacher, P. G., Freeman, S. P., Braun, S. E., ... Brown, K. W. (2019). Brief mindfulness training enhances cognitive control in socioemotional contexts: Behavioral and neural evidence. PLoS One, 14(7). https://doi. org/10.1371/journal.pone.0219862

Holmes, S. E., Hinz, R., Conen, S., Gregory, C. J., Matthews, J. C., Anton-Rodriguez, J. M., ... Talbot, P. S. (2018). Elevated Translocator Protein in Anterior Cingulate in Major Depression and a Role for Inflammation in Suicidal Thinking: A Positron Emission Tomography Study. Biological Research, 83(1), 61-69. https://doi.org/10.1016/j.biopsych.2017.08.005

Holzel, B. K., Lazar, S. W., Gard, T., Schuman-Olivier, Z., Vago, D. R., \& Ott, U. (2011). How does mindfulness meditation work? Proposing mechanisms of action from a conceptual and neural perspective. Perspectives on Psychological Science, 6(6), 537-559. https://doi. org/10.1177/1745691611419671

Hori, H., \& Kim, Y. (2019). Inflammation and post-traumatic stress disorder. Psychiatry and Clinical Neurosciences, 73(4), 143-153. https://doi.org/10.1111/pcn.12820

Hoskins, M., Pearce, J., Bethell, A., Dankova, L., Barbui, C., Tol, W. A., ... Chen, H. (2015). Pharmacotherapy for post-traumatic stress disorder: Systematic review and meta-analysis. The British Journal of Psychiatry, 206(2), 93-100. https://doi.org/10.1192/bjp.bp.114. 148551

Hughes, K. C., \& Shin, L. M. (2011). Functional neuroimaging studies of posttramatic stress disorder. Expert Review of Neurotherapeutics, 11(2), 275-285. https://doi.org/10.1586/ern.10.198

Hunt, S., Sun, Y., Kucukdereli, H., Klein, R., \& Sah, P. (2017). Intrinsic circuits in the lateral central amygdala. eNeuro, 4(4), 1-18. https:// doi.org/10.1523/ENEURO.0367-16.2017

Hussein, S., Dalton, B., Willmund, G. D., Ibrahim, M. A. A., \& Himmerich, H. (2017). A systematic review of tumor necrosis factor-alpha in post-traumatic stress disorder: Evidence from human and animal studies. Psychiatria Danubina, 29(4), 407-420. https:// doi.org/10.24869/psyd.2017.407

Huston, J. M., \& Tracey, K. J. (2011). The pulse of inflammation: Heart rate variability, the cholinergic anti-inflammatory pathway and implications for therapy. Journal of Internal Medicine, 269(1), 45-53. https://doi.org/10.1111/j.1365-2796.2010.02321.x

Imai, R., Hori, H., Itoh, M., Lin, M., Niwa, M., Ino, K., ... Kim, Y. (2018). Inflammatory markers and their possible effects on cognitive function in women with posttraumatic stress disorder. Journal of Psychiatric Research, 102, 192-200. https://doi.org/10.1016/j. jpsychires.2018.04.009

Inagaki, T. K., Muscatell, K. A., Irwin, M. R., Cole, S. W., \& Eisenberger, N. I. (2012). Inflammation selectively enhances amygdala activity to socially threatening images. Neuroimage, 59(4), 3222-3226. https:// doi.org/10.1016/j.neuroimage.2011.10.090

Irwin, M. R., \& Cole, S. W. (2011). Reciprocal regulation of the neural and innate immune systems. Nature Reviews. Immunology, 11(9), 625-632. https://doi.org/10.1038/nri3042

Jak, A. J., Aupperle, R., Rodgers, C. S., Lang, A. J., Schiehser, D. M., Norman, S. B., \& Twamley, E. W. (2015). Evaluation of a hybrid treatment for Veterans with comorbid traumatic brain injury and posttraumatic stress disorder: Study protocol for a randomized controlled trial. Contemporary Clinical Trials, 45(Pt B), 210-216. https://doi.org/10.1016/j.cct.2015.10.009
Jakovljevic, M., Brajkovic, L., Loncar, M., \& Cima, A. (2012). Postraumatic stress disorders (PTSD) between fallacy and facts: What we know and what we don ' t know? Psychiatria Danubina, 24(3), 241-245.

Jelinek, L., Jacobsen, D., Kellner, M., Larbig, F., Biesold, K. H., Barre, K., \& Moritz, S. (2006). Verbal and nonverbal memory functioning in posttraumatic stress disorder (PTSD). Journal of Clinical and Experimental Neuropsychology, 28(6), 940-948. https://doi.org/10. 1080/13803390591004347

Jenkins, M. A., Langlais, P. J., Delis, D., \& Cohen, R. (1998). Learning and memory in rape victims with posttraumatic stress disorder. The American Journal of Psychiatry, 155(2), 278-279. https://doi.org/ 10.1176/ajp.155.2.278

Jergovic, M., Bendelja, K., Savic Mlakar, A., Vojvoda, V., Aberle, N., Jovanovic, T., ... Vidovic, A. (2015). Circulating levels of hormones, lipids, and immune mediators in post-traumatic stress disorder - a 3-month follow-up study. Frontiers in Psychiatry, 6, 49. https://doi.org/10.3389/fpsyt.2015.00049

Jester, D. J., Rozek, E. K., \& McKelley, R. A. (2019). Heart rate variability biofeedback: Implications for cognitive and psychiatric effects in older adults. Aging \& Mental Health, 23(5), 574-580. https://doi. org/10.1080/13607863.2018.1432031

Jha, A. P., Stanley, E. A., Kiyonaga, A., Wong, L., \& Gelfand, L. (2010). Examining the protective effects of mindfulness training on working memory capacity and affective experience. Emotion, 10(1), 54-64. https://doi.org/10.1037/a0018438

Johansen, J. P., Hamanaka, H., Monfils, M. H., Behnia, R., Deisseroth, K., Blair, H. T., \& LeDoux, J. E. (2010). Optical activation of lateral amygdala pyramidal cells instructs associative fear learning. Proceedings of the National Academy of Sciences of the United States of America, 107(28), 12692-12697. https://doi.org/10.1073/ pnas. 1002418107

Johnsen, G. E., \& Asbjornsen, A. E. (2009). Verbal learning and memory impairments in posttraumatic stress disorder: The role of encoding strategies. Psychiatry Research, 165(1-2), 68-77. https://doi.org/10. 1016/j.psychres.2008.01.001

Johnsen, G. E., Kanagaratnam, P., \& Asbjornsen, A. E. (2008). Memory impairments in posttraumatic stress disorder are related to depression. Journal of Anxiety Disorders, 22(3), 464-474. https://doi.org/ 10.1016/j.janxdis.2007.04.007

Johnson, J. D., Bernard, D. F., Kulp, A. C., \& Mehta, D. M. (2019). Neuroendocrine regulation of brain cytokines after psychological stress. Journal of the Endocrine Society, 3(7), 1302-1320. https:// doi.org/10.1210/js.2019-00053

Jones, K. A., \& Thomsen, C. (2013). The role of the innate immune system in psychiatric disorders. Molecular and Cellular Neurosciences, 53, 52-62. https://doi.org/10.1016/j.mcn.2012.10. 002

Jurick, S. M., Crocker, L. D., Sanderson-Cimino, M., Keller, A. V., Trenova, L. S., Boyd, B. L., ... Jak, A. J. (2018). Contributions to executive dysfunction in operation enduring freedom/operation iraqi freedom veterans with posttraumatic stress disorder and history of mild traumatic brain injury. The Journal of Head Trauma Rehabilitation, 33(2), E41-E52. https://doi.org/10.1097/HTR. 0000000000000313

Kanefsky, R. Motamedi, V., Mithani, S., Mysliwiec, V., Gill, J. M., Pattinson, C. L. (2019). Mild traumatic brain injuries with loss of consciousness are associated with increased inflammation and pain in military personnel. Psychiatry Research, 279, 34-39. https://doi. org/10.1016/j.psychres.2019.07.001

Kao, S., Westfall, D. R., Soneson, J., Gurd, B., \& Hillman, C. H. (2017). Comparison of the acute effects of high-intensity interval training and continuous aerobic walking on inhibitory control. Psychophysiology, 54(9), 1335-1345. https://doi.org/10.1111/psyp. 12889 
Kearney, D. J., \& Simpson, T. L. (2015). Broadening the approach to posttraumatic stress disorder and the consequences of trauma. JAMA, 314(5), 453-455. https://doi.org/10.1001/jama.2015.7522

Kemp, A., Quintana, D., Felmingham, K., Matthews, S., \& Jelinek, H. (2012). Depression, comorbid anxiety disorders, and heart rate variability in physically healthy, unmedicated patients: Implications for cardiovascular risk. PLoS One, 7(2), e30777. https://doi.org/10. 1371/journal.pone.0030777

Khoury, N. M., Marvar, P. J., Gillespie, C. F., Wingo, A., Schwartz, A., Bradley, B., ... Ressler, K. J. (2012). The renin-angiotensin pathway in posttraumatic stress disorder: Angiotensin-converting enzyme inhibitors and angiotensin receptor blockers are associated with fewer traumatic stress symptoms. The Journal of Clinical Psychiatry, 73(6), 849-855. https://doi.org/10.4088/JCP.11 m07316

Kim, Y. K., Amidfar, M., \& Won, E. (2019). A review on inflammatory cytokine-induced alterations of the brain as potential neural biomarkers in post-traumatic stress disorder. Progress in NeuroPsychopharmacology \& Biological Psychiatry, 91, 103-112. https://doi.org/10.1016/j.pnpbp.2018.06.008

Kirk-Sanchez, N. J., \& McGough, E. L. (2014). Physical exercise and cognitive performance in the elderly: Current perspectives. Clinical Interventions in Aging, 9, 51-62. https://doi.org/10.2147/CIA. S39506

Knappe, F., Colledge, F. \& Gerber, M. (2019). Impact of an 8-Week Exercise and Sport Intervention on Post-Traumatic Stress Disorder Symptoms, Mental Health, and Physical Fitness among Male Refugees Living in a Greek Refugee Camp. International Journal of Environmental Research, 16(20), E3904.

Knight, D. C., Smith, C. N., Cheng, D. T., Stein, E. A., \& Helmstetter, F. J. (2004). Amygdala and hippocampal activity during acquisition and extinction of human fear conditioning. Cognitive, Affective, \& Behavioral Neuroscience, 4(3), 317-325. https://doi.org/10.3758/ cabn.4.3.317

Koso, M., \& Hansen, S. (2006). Executive function and memory in posttraumatic stress disorder: A study of Bosnian war veterans. European Psychiatry, 21(3), 167-173. https://doi.org/10.1016/j. eurpsy.2005.06.004

Kranjac, D., McLinden, K. A., Deodati, L. E., Papini, M. R., Chumley, M. J., \& Boehm, G. W. (2012). Peripheral bacterial endotoxin administration triggers both memory consolidation and reconsolidation deficits in mice. Brain, Behavior, and Immunity, 26(1), 109-121. https://doi.org/10.1016/j.bbi.2011.08.005

Kraynak, T. E., Marsland, A. L., Hanson, J. L., \& Gianaros, P. J. (2019). Retrospectively reported childhood physical abuse, systemic inflammation, and resting corticolimbic connectivity in midlife adults. Brain, Behavior, and Immunity, 82, 203-213. https://doi.org/10. 1016/j.bbi.2019.08.186

Krogh, J., Benros, M. E., Jorgensen, M. B., Vesterager, L., Elfving, B., \& Nordentoft, M. (2014). The association between depressive symptoms, cognitive function, and inflammation in major depression. Brain, Behavior, and Immunity, 35, 70-76. https://doi.org/10.1016/ j.bbi.2013.08.014

Kuhn, S., \& Gallinat, J. (2013). Gray matter correlates of posttraumatic stress disorder: A quantitative meta-analysis. Biological Psychiatry, 73(1), 70-74. https://doi.org/10.1016/j.biopsych.2012.06.029

Lagarde, G., Doyon, J., \& Brunet, A. (2010). Memory and executive dysfunctions associated with acute posttraumatic stress disorder. Psychiatry Research, 177(1-2), 144-149. https://doi.org/10.1016/j. psychres.2009.02.002

Lampit, A., Hallock, H., \& Valenzuela, M. (2014). Computerized cognitive training in cognitively healthy older adults: A systematic review and meta-analysis of effect modifiers. PLoS Medicine, 11(11), e1001756. https://doi.org/10.1371/journal.pmed.1001756

Latack, J. A., Moyer, A., Simon, V. A., \& Davila, J. (2017). Attentional bias for sexual threat among sexual victimization survivors: A meta- analytic review. Trauma Violence Abuse, 18(2), 172-184. https:// doi.org/10.1177/1524838015602737

Lee, C., \& Giuliani, F. (2019). The role of inflammation in depression and fatigue. Frontiers in Immunology, 10, 1696. https://doi.org/10.3389/ fimmu.2019.01696

Lee, D. J., Schnitzlein, C. W., Wolf, J. P., Vythilingam, M., Rasmusson, A. M., \& Hoge, C. W. (2016). Psychotherapy versus pharmacotherapy for posttraumatic stress disorder: Systemic review and metaanalyses to determine first-line treatments. Depression and Anxiety, 33(9), 792-806.

Lehrer, P., \& Gevirtz, R. (2014). Heart rate variability biofeedback: How and why does it work? Frontiers in Psychology, 5, 756. https://doi. org/10.3389/fpsyg.2014.00756

Lehrer, P., Karavidas, M. K., Lu, S. E., Coyle, S. M., Oikawa, L. O., Macor, M., ... Lowry, S. F. (2010). Voluntarily produced increases in heart rate variability modulate autonomic effects of endotoxin induced systemic inflammation: An exploratory study. Applied Psychophysiology and Biofeedback, 35(4), 303-315. https://doi. org/10.1007/s10484-010-9139-5

Lehrer, P., Vaschillo, E., Vaschillo, B., Lu, S.-E., Eckberg, D., Edelberg, R., ... Hamer, R. (2003). Heart rate variability biofeedback increases baroreflex gain and peak expiratory flow. Psychosomatic Medicine, 65(5), 796-805. https://doi.org/10.1097/01.Psy.0000089200.81962. 19

Lehrer, P. M. (2018). Heart rate variability biofeedback and other psychophysiological procedures as important elements in psychotherapy. International Journal of Psychophysiology, 131, 89-95. https://doi. org/10.1016/j.ijpsycho.2017.09.012

Leong, Y. C., Radulescu, A., Daniel, R., DeWoskin, V., \& Niv, Y. (2017). Dynamic interaction between reinforcement learning and attention in multidimensional environments. Neuron, 93(2), 451-463. https:// doi.org/10.1016/j.neuron.2016.12.040

Leskin, L. P., \& White, P. M. (2007). Attentional networks reveal executive function deficits in posttraumatic stress disorder. Neuropsychology, 21(3), 275-284. https://doi.org/10.1037/08944105.21.3.275

Li, Y., Liu, F., Zhang, Q., Liu, X., \& Wei, P. (2018). The Effect of Mindfulness Training on Proactive and Reactive Cognitive Control. Frontiers in Psychology, 9, 1002. https://doi.org/10.3389/ fpsyg.2018.01002

Ligeza, T. S., Maciejczyk, M., Kalamala, P., Szygula, Z., \& Wyczesany, M. (2018). Moderate-intensity exercise boosts the N2 neural inhibition marker: A randomized and counterbalanced ERP study with precisely controlled exercise intensity. Biological Psychology, 135, 170-179. https://doi.org/10.1016/j.biopsycho.2018.04.003

Lin, I. M., Fan, S. Y., Yen, C. F., Yeh, Y. C., Tang, T. C., Huang, M. F., ... Tsai, Y. C. (2019). Heart Rate Variability Biofeedback Increased Autonomic Activation and Improved Symptoms of Depression and Insomnia among Patients with Major Depression Disorder. Clinical Psychopharmacology and Neuroscience, 17(2), 222-232. https://doi.org/10.9758/cpn.2019.17.2.222

Lin, T., Liu, G. A., Perez, E., Rainer, R. D., Febo, M., Cruz-Almeida, Y., \& Ebner, N. C. (2018). Systemic inflammation mediates age-related cognitive deficits. Frontiers in Aging Neuroscience, 10, 236. https:// doi.org/10.3389/fnagi.2018.00236

Linnman, C., Rougemont-Bücking, A., Beucke, J. C., Zeffiro, T. A., \& Milad, M. R. (2011). Unconditioned responses and functional fear networks in human classical conditioning. Behavioural Brain Research, 221, 237-245. https://doi.org/10.1016/j.bbr.2011.02.045.

Linnman, C., Zeffiro, T. A., Pitman, R. K., \& Milad, M. R. (2011). An fMRI study of unconditioned responses in post-traumatic stress disorder. Biology of Mood and Anxiety Disorders, 1-8. https://doi.org/ 10.1186/2045-5380-1-8

Linnman, C., Zeidan, M. A., Furtak, S. C., Pitman, R. K., Quirk, G. J., \& Milad, M. R. (2012). Resting amygdala and medial prefrontal metabolism predicts functional activation of the fear extinction circuit. 
The American Journal of Psychiatry, 169, 415-423. https://oi.org/ 10.1176/appi.ajp.2011.10121780

Linnman, C., Zeidan, M. A., Pitman, R. K., and Milad, M. R. (2012). Resting cerebral metabolism correlates with skin conductance and functional brain activation during fear conditioning. Biological Psychology, 89, 450-459. https://doi.org/10.1016/j.biopsycho. 2011.12.012

Lisboa, S. F., Niraula, A., Resstel, L. B., Guimaraes, F. S., Godbout, J. P., \& Sheridan, J. F. (2018). Repeated social defeat-induced neuroinflammation, anxiety-like behavior and resistance to fear extinction were attenuated by the cannabinoid receptor agonist WIN55,212-2. Neuropsychopharmacology, 43(9), 1924-1933. https://doi.org/10. 1038/s41386-018-0064-2

Loayza Careaga, M. B., Neves Girardi, C. E., \& Suchecki, D. (2016). Understanding posttraumatic stress disorder trhough fear conditioning, extinction and reconsolidation. Neuroscience and Biobehavioral Reviews, 71, 48-57. https://doi.org/10.1016/j. neubiorev.2016.08.023

Logue, M. W., van Rooij, S. J. H., Dennis, E. L., Davis, S. L., Hayes, J. P., Stevens, J. S., ... Morey, R. A. (2018). Smaller hippocampal volume in posttraumatic stress disorder: A multisite ENIGMA-PGC study: subcortical volumetry results from posttraumatic stress disorder consortia. Biological Psychiatry, 83(3), 244-253. https://doi.org/10. 1016/j.biopsych.2017.09.006

LoSavio, S. T., Dillon, K. H., \& Resick, P. A. (2017). Cognitive factors in the development, maintenance, and treatment of post-traumatic stress disorder. Current Opinion in Psychology, 14, 18-22. https:// doi.org/10.1016/j.copsyc.2016.09.006

Luine, V., Villegas, M., Martinez, C., \& McEwen, B. S. (1994). Repeated stress causes reversible impairments of spatial memory performance. Brain Research, 639, 167-170.

Luo, H., Hu, X., Liu, X., Ma, X., Guo, W., Qiu, C., ... Li, T. (2012). Hair cortisol level as a biomarker for altered hypothalamic-pituitaryadrenal activity in female adolescents with posttraumatic stress disorder after the 2008 Wenchuan earthquake. Biological Psychiatry, 72(1), 65-69. https://doi.org/10.1016/j.biopsych.2011.12.020

Maeng, L. Y. \& Milad, M. R. (2017). Post-traumatic stress disorder: The relationship between fear response and chronic stress. Chronic Stress, 1, 1-13. https://doi.org/10.1177/2470547017713297

Manassero, E., Renna, A., Milano, L., \& Sacchetti, B. (2018). Lateral and basal amygdala account for opposite behavioral responses during the long-term expression of fearful memories. Scientific Reports, 8, 518. https://doi.org/10.1038/s41598-017-19074-3

Mandolesi, L., Polverino, A., Montuori, S., Foti, F., Ferraioli, G., Sorrentino, P., \& Sorrentino., G. (2018). Effects of physical exercise on cognitive functioning and wellbeing: Biological and psychological benefits. Frontiers in Psychology, 9, 509. https://doi.org/10. 3389/fpsyg.2018.00509

Marek, R., \& Sah, P. (2018). Neural circuits mediating fear learning and extinction. Advances in Neurobiology, 21, 35-48. https://doi.org/10. 1007/978-3-319-94593-4_2.

Marsland, A. L., Petersen, K. L., Sathanoori, R., Muldoon, M. F., Neumann, S. A., Ryan, C., ... Manuck, S. B. (2006). Interleukin-6 covaries inversely with cognitive performance among middle-aged community volunteers. Psychosomatic Medicine, 68, 895-903.

Marvar, P. J., \& Harrison, D. G. (2012). Inflammation, immunity and the autonomic nervous system. In D. Robertson, I. Biaggioni, G. Burnstock, P. A. Low, \& J. F. R. Paton (Eds.), Primer on thr Autonomic Nervous System (pp. 325-329). London: Elsevier Inc.

Marx, B. P., Brailey, K., Proctor, S. P., Macdonald, H. Z., Graefe, A. C., Amoroso, P., ... Vasterling, J. J. (2009). Association of time since deployment, combat intensity, and posttraumatic stress symptoms with neuropsychological outcomes following Iraq war deployment. Archives of General Psychiatry, 66(9), 996-1004. https://doi.org/10. 1001/archgenpsychiatry.2009.109
McCanlies, E. C., Araia, S. K., Joseph, P. N., Mnatsakanova, A., Andrew, M. E., Burchfiel, C. M., \& Violanti, J. M. (2011). C-reactive protein, interleukin-6, and posttraumatic stress disorder symptomology in urban police officers. Cytokine, 55(1), 74-78. https://doi.org/10. 1016/j.cyto.2011.03.025

McEwen, B. S. (2000). The neurobiology of stress: From serendipity to clinical relevance. Brain Research, 886, 172-189.

McFarlane, A. C. (2010). The long-term costs of traumatic stress: Intertwined physical and psychological consequences. World Psychiatry, 9, 3-10. https://doi.org/10.1002/j.2051-5545.2010. tb00254.x

Mehta, N. D., Haroon, E., Xu, X., Woolwine, B. J., Li, Z., \& Felger, J. C. (2018). Inflammation negatively correlates with amygdalaventromedial prefrontal functional connectivity in association with anxiety in patients with depression: Preliminary results. Brain, Behavior, and Immunity, 73, 725-730. https://doi.org/10.1016/j. bbi.2018.07.026

Mellon, S. H., Gautman, A., Hammamieh, R., Jett, M., \& Wolkowitz, O. M. (2018). Metabolism, motabolomics, and inflammation in posttraumatic stress disorder. Biological Psychiatry, 83, 866-875. https://doi.org/10.1016/j.biopsych.2018.02.007

Michopoulos, V., Powers, A., Gillespie, C. F., Ressler, K. J., \& Jovanovic, T. (2017). Inflammation in fear- and anxiety-based disorders: PTSD, GAD, and beyond. Neuropsychopharmacology, 42(1), 254-270. https://doi.org/10.1038/npp.2016.146

Michopoulos, V., Rothbaum, A. O., Jovanovic, T., Almli, L. M., Bradley, B., Rothbaum, B. O., ... Ressler, K. J. (2015). Association of CRP genetic variation and CRP level with elevated PTSD symptoms and physiological responses in a civilian population with high levels of trauma. The American Journal of Psychiatry, 172(4), 353-362. https://doi.org/10.1176/appi.ajp.2014.14020263

Milad, M. R., Pitman, R. K., Ellis, C. B., Gold, A. L., Shin, L. M., Lasko, N. B., ... Rauch, S. L. (2009). Neurobiological basis of failure to recall extinction memory in posttraumatic stress disorder. Biological Psychiatry, 66(12), 1075-1082. https://doi.org/10.1016/j.biopsych. 2009.06.026

Milad, M. R., Quinn, B. T., Pitman, R. K., Orr, S. P., Fischl, B., \& Rauch, S. L. (2005). Thickness of ventromedial prefrontal cortex in humans is correlated with extinction memory. Proceedings of the National Academy of Sciences of the United States of America, 102(30), 10706-10711. https://doi.org/10.1073/pnas.0502441102

Milad, M. R., \& Quirk, G. J. (2012). Fear extinction as a model for translational neuroscience: Ten years of progress. Annual Review of Psychology, 63, 129-151. https://doi.org/10.1146/annurev. psych.121208.131631

Milad, M. R., Wright, C. I., Orr, S. P., Pitman, R. K., Quirk, G. J., \& Rauch, S. L. (2007). Recall of fear extinction in humans activates the ventromedial prefrontal cortex and hippocampus in concert. Biological Psychiatry, 162(5), 446-454.

Miller, A. H., \& Raison, C. L. (2016). The role of inflammation in depression: from evolutionary imperative to modern treatment target. Nature Reviews Immunology, 16(1), 22-34. https://doi.org/10.1038/ nri.2015.5

Morey, R. A., Clarke, E. K., Haswell, C. C., Phillips, R. D., Clausen, A. N., Mufford, M. S., ... LaBar, K. S. (2019). Amygdala nuclei volume and shape in military veterans with posttraumatic stress disorder. Biological Psychiatry, S2451-9022(19), 30342-30348. https:// doi.org/10.1016/j.bpsc.2019.11.016

Morey, R. A., Haswell, C. C., Hooper, S. R., \& De Bellis, M. D. (2016). Amygdala, hippocampus, and ventral medial prefrontal cortex volumes differ in maltreated youth with and without chronic posttraumatic stress disorder. Neuropsychopharmacology, 41(3), 791-801.

Morimoto, S. S., Wexler, B. E., \& Alexopoulos, G. S. (2012). Neuroplasticity-based computerized cognitive remediation for geriatric depression. International Journal of Geriatric Psychiatry, 27(12), 1239-1247. https://doi.org/10.1002/gps.3776 
Motter, J. N., Pimontel, M. A., Rindskopf, D., Devanand, D. P., Doraiswamy, P. M., \& Sneed, J. R. (2016). Computerized cognitive training and functional recovery in major depressive disorder: A meta-analysis. Journal of Affective Disorders, 189, 184-191. https://doi.org/10.1016/j.jad.2015.09.022

Muscatell, K. A., Dedovic, K., Slavich, G. M., Jarcho, M. R., Breen, E. C., Bower, J. E., ... Eisenberger, N. I. (2015). Greater amygdala activity and dorsomedial prefrontal-amygdala coupling are associated with enhanced inflammatory responses to stress. Brain, Behavior, and Immunity, 43, 46-53. https://doi.org/10.1016/j.bbi.2014.06.201

Muscatell, K. A., Moieni, M., Inagaki, T. K., Dutcher, J. M., Jevtic, I., Breen, E. C., ... Eisenberger, N. I. (2016). Exposure to an inflammatory challenge enhances neural sensitivity to negative and positive social feedback. Brain, Behavior, and Immunity, 547, 21-29. https://doi.org/10.1016/j.bbi.2016.03.022

Nagpal, M., Gleichauf, K., \& Ginsberg, J. (2013). Meta-analysis of heart rate variability as a psychophysiological indicator of posttraumatic stress disorder. Trauma \& Treatment, 03(01). https://doi.org/10. 4172/2167-1222.1000182

Nelson, L. A., Yoash-Gantz, R. E., Pickett, T. C., \& Campbell, T. A. (2009). Relationship between processing speed and executive functioning performance among $\mathrm{OEF} / \mathrm{OIF}$ veterans: Implications for postdeployment rehabilitation. The Journal of Head Trauma Rehabilitation, 24(1), 32-40. https://doi.org/10.1097/HTR. 0b013e3181957016

Nylocks, K. M., Michopoulos, V., Rothbaum, A. O., Almli, L., Gillespie, C. F., Wingo, A., ... Ressler, K. J. (2015). An angiotensinconverting enzyme (ACE) polymorphism may mitigate the effects of angiotensin-pathway medications on posttraumatic stress symptoms. American Journal of Medical Genetics. Part B, Neuropsychiatric Genetics, 168B(4), 307-315. https://doi.org/10. 1002/ajmg.b.32313

Oberste, M., Javelle, F., Sharma, S., Joisten, N., Walzik, D., Bloch, W., \& Zimmer, P. (2019). Effects and moderators of acute aerobic exercise on subsequent interference control: A systematic review and metaanalysis. Frontiers in Psychology, 10, 2616. https://doi.org/10.3389/ fpsyg.2019.02616

O'Connor, M. F., Irwin, M. R., Wellisch, D.K. (2009). When grief heats up: Proinflammatory cytokines predict regional brain activation. NeuroImage, 47, 891-896. https://doi.org/10.1016/j.neuroimage. 2009.05.049

O'Donovan, A., Chao, L. L., Paulson, J., Samuelson, K. W., Shigenaga, J. K., Grunfeld, C., ... Neylan, T. C. (2015). Altered inflammatory activity associated with reduced hippocampal volume and more severe posttraumatic stress symptoms in Gulf War veterans. Psychoneuroendocrinology, 51, 557-566. https://doi.org/10.1016/j. psyneuen.2014.11.010

Oliveira, L., Costa-Neto, C. M., Nakaie, C. R., Schreier, S., Shimuta, S. I., \& Paiva, A. C. M. (2007). The angiotensin ii AT1 receptor structureactivity correlations in the light of rhodopsin structure. Physiological Reviews, 87, 565-592. https://doi.org/10.1152/ physrev.00040.2005

Owens, M., Koster, E. H., \& Derakshan, N. (2013). Improving attention control in dysphoria through cognitive training: Transfer effects on working memory capacity and filtering efficiency. Psychophysiology, 50(3), 297-307. https://doi.org/10.1111/psyp. 12010

Pace, T. W., \& Heim, C. M. (2011). A short review on the psychoneuroimmunology of posttraumatic stress disorder: From risk factors to medical comorbidities. Brain, Behavior, and Immunity, 25(1), 6-13. https://doi.org/10.1016/j.bbi.2010.10.003

Pan, X., Wang, Z., Wu, X., Wen, S. W., \& Liu, A. (2018). Salivary cortisol in post-traumatic stress disorder: A systematic review and meta-analysis. BMC Psychiatry, 18, 324. https://doi.org/10.1186/ s12888-018-1910-9
Pare, D. C., Collins D. R. (2000). Neuronal correlates of fear in the lateral amygdala multiple extracellular recordings in conscious cats. The Journal of Neuroscience, 20(7), 2701-2710.

Parent, M. A., Wang, L., Su, J., Netoff, T., \& Yuan, L. L. (2010). Identification of the hippocampal input to medial prefrontal cortex in vitro. Cerebral Cortex, 20(2), 393-403. https://doi.org/10.1093/ cercor/bhp108

Park, G., Vasey, M. W., Van Bavel, J. J., \& Thayer, J. F. (2013). Cardiac vagal tone is correlated with selective attention to neutral distractors under load. Psychophysiology, 50(4), 398-406. https://doi.org/10. 1111/psyp.12029

Park, S. M., Choi, J. S., Lee, J. S., Lee, J. Y., Lee, S., \& Jung, H. Y. (2018). Impaired executive functioning of sexual assault survivors with acute stress disorder. Journal of Clinical Medicine, 7(10). https:// doi.org/10.3390/jcm7100362

Passos, I. C., Vasconcelos-Moreno, M. P., Costa, L. G., Kunz, M., Brietzke, E., Quevedo, J., ... Kauer-Sant'Anna, M. (2015). Inflammatory markers in post-traumatic stress disorder: A systematic review, meta-analysis, and meta-regression. Lancet Psychiatry, 2, 1002-1012. https://doi.org/10.1016/S2215-0366(15)00309-0

Pavlov, V. A., \& Tracey, K. J. (2012). The vagus nerve and the inflammatory reflex-linking immunity and metabolism. Nature Reviews. Endocrinology, 8(12), 743-754. https://doi.org/10.1038/nrendo. 2012.189

Pedersen, B. K. (2017). Anti-inflammatory effects of exercise: role in diabetes and cardiovascular disease. European Journal of Clinical Investigation, 47(8), 600-611. https://doi.org/10.1111/eci.12781

Peters, A. T., Ren, X., Bessette, K. L., Goldstein, B. I., West, A. E., Langenecker, S. A., \& Pandey, G. N. (2019). Interplay between pro-inflammatory cytokines, childhood trauma, and executive function in depressed adolescents. Journal of Psychiatric Research, 114, 1-10. https://doi.org/10.1016/j.jpsychires.2019.03.030

Pham, H., Chong, B., Vincenti, R., \& Slice, L. W. (2008). Ang II and EGF synergistically induce COX-2 expression via CREB in intestinal epithelial cells. Journal of Cellular Physiology, 214(1), 96-109. https://doi.org/10.1002/jcp.21167

Phelps, E. A., Delgado, M. R., Nearing, K. I., \& LeDoux, J. E. (2004). Extinction learning in humans: role of the amygdala and vmPFC. Neuron, 43(6), 897-905. https://doi.org/10.1016/j.neuron.2004.08. 042

Pietrzak, R. H., Averill, L. A., Abdallah, C. G., Neumeister, A., Krystal, J. H., Levy, I., \& Harpaz-Rotem, I. (2015). Amygdala-hippocampal volume and the phenotypic heterogeneity of posttraumatic stress disorder. JAMA Psychiatry, 72(4), 396-398.

Pimontel, M. A., Culang-Reinlieb, M. E., Morimoto, S. S., \& Sneed, J. R. (2012). Executive dysfunction and treatment response in late-life depression. International Journal of Geriatric Psychiatry, 27(9), 893-899. https://doi.org/10.1002/gps.2808

Pimontel, M. A., Rindskopf, D., Rutherford, B. R., Brown, P. J., Roose, S. P., \& Sneed, J. R. (2016). A Meta-analysis of executive dysfunction and antidepressant treatment response in late-life depression. American Journal of Geriatric Psychiatry, 24(1), 31-41. https:// doi.org/10.1016/j.jagp.2015.05.010

Plantinga, L., Bremner, J. D., Miller, A. H., Jones, D. P., Veledar, E., Goldberg, J., \& Vaccarino, V. (2013). Association between posttraumatic stress disorder and inflammation: A twin study. Brain, Behavior, and Immunity, 30, 125-132. https://doi.org/10.1016/j. bbi.2013.01.081

Polak, A. R., Witteveen, A. B., Reitsma, J. B., \& Olff, M. (2012). The role of executive function in posttraumatic stress disorder: A systematic review. Journal of Affective Disorders, 141(1), 11-21. https://doi. org/10.1016/j.jad.2012.01.001

Prager, G., Hadamitzky, M., Engler, A., Doenlen, R., Wirth, T., PachecoLopez, G., ... Engler, H. (2013). Amygdaloid signature of peripheral immune activation by bacterial lipopolysaccharide or 
staphylococcal enterotoxin B. Journal of Neuroimmune Pharmacology, 8(1), 42-50. https://doi.org/10.1007/s11481-0129373-0.

Prinsloo, G. E., Rauch, H. G. L., Lambert, M. I., Muench, F., Noakes, T. D., \& Derman, W. E. (2011). The effect of short duration heart rate variability (HRV) biofeedback on cognitive performance during laboratory induced cognitive stress. Applied Cognitive Psychology, 25(5), 792-801. https://doi.org/10.1002/acp.1750

Quinones, M. M., Maldonado, L., Velazquez, B., \& Porter, J. T. (2016). Candesartan ameliorates impaired fear extinction induced by innate immune activation. Brain, Behavior, and Immunity, 52, 169-177. https://doi.org/10.1016/j.bbi.2015.10.017

Qureshi, S. U., Long, M. E., Bradshaw, M. R., Pyne, J. M., Margruder, K. M., Kimbrell, T., ... Kunik, M. E. (2011). Does PTSD impair cognition beyond the effect of trauma? The Journal of Neuropsychiatry and Clinical Neurosciences, 23, 16-28.

Rathbone, A. T. L., Tharmaradinam, S., Jiang, S., Rathbone, M. P., \& Kumbhare, D. A. (2015). A review of the neuro- and systemic inflammnatory responses in post concussion symtpoms: Introductions of the "post-inflammatory brain syndrome" PIBS. Brain, Behavior, and Immunity, 46, 1-16. https://doi.org/10.1016/j. bbi.2015.02.009

Roberge, M. A., Dupuis, G., \& Marchand, A. (2010). Post-traumatic stress disorder following myocardial infarction: Prevalence and risk factors. The Canadian Journal of Cardiology, 26(5), e170-e175.

Roozendaal, B., McEwen, B. S., \& Chattarji, S. (2009). Stress, memory and the amygdala. Nature Reviews. Neuroscience, 10(6), 423-433. https://doi.org/10.1038/nrn2651

Rougemont-Bucking, A., Linnman, C., Zeffiro, T. A., Zeidan, M. A., Lebron-Milad, K., Rodriguez-Romaguera, J., ... Milad, M. R. (2011). Altered processing of contextual information during fear extinction in PTSD: An fMRI study. CNS Neuroscience \& Therapeutics, 17(4), 227-236. https://doi.org/10.1111/j.1755-5949. 2010.00152.x

Rubin, M., Shvil, E., Papini, S., Chhetry, B. T., Helpman, L., Markowitz, J. C., ... Neria, Y. (2016). Greater hippocampal volume is associated with PTSD treatment response. Psychiatry Research: Neuroimaging, 252, 36-39. https://doi.org/10.1016/j.pscychresns. 2016.05.001

Sadeh, N., Spielberg, J. M., Warren, S. L., Miller, G. A., \& Heller, W. (2014). Aberrant neural connectivity during emotional processing associated with posttraumatic stress. Clinical Psychological Science: A Journal of the Association for Psychological Science, 2(6), 748-755. https://doi.org/10.1177/2167702614530113

Salim, S., Chugh, G., \& Asghar, M. (2012). Inflammation in anxiety. Advances in Protein Chemistry and Structural Biology, 88, 1-25. https://doi.org/10.1016/B978-0-12-398314-5.00001-5

Sampath, D., Sathyanesan, M., \& Newton, S. S. (2017). Cognitive dysfunction in major depression and Alzheimer's disease is associated with hippocampal-prefrontal cortex dysconnectivity. Neuropsychiatric Disease and Treatment, 13, 1509-1519. https:// doi.org/10.2147/NDT.S136122

Samuelson, K. W. (2011). Post-traumatic stress disorder and declarative memory functioning: A review. Dialogues in Clinical Neuroscience, 13(3), 346-351.

Samuelson, K. W., Metzler, T. J., Rothlind, J. C.G.., Neylan, T. C., Lenoci, M., Henn-Haase, C., ..., Marmar, C. R. (2006). Neuropsychological functioning in posttraumatic stress disorder and alcohol abuse. Neuropsychology, 20(6), 716-726.

Schelling, G., Roozendaal, B., Krauseneck, T., Schmoelz, M., DE Quervain D \& Briegel, J. (2006). Efficacy of hydrocortisone in preventing posttraumatic stress disorder following critical illness and major surgery. Annals of the New York Academy of Sciences, 1071, 46-53. https://doi.org/10.1196/annals.1364.005

Schnurr, P. P. (2015). Understanding patways from traumatic exposure to physical health. In U. Schnyder \& M. Cloitre (Eds.), Evidence Based
Treatments for Trauma-Related Psychological Disorders (pp. 87103). Springer, Cham.

Schottenbauer, M. A., Glass, C. R., Arnkoff, D. B., Tendick, V., \& Gray, S. H. (2008). Nonresponse and dropout rates in outcome studies on PTSD: Review and methodological considerations. Psychiatry, 71(2), 134-168. https://doi.org/10.1521/psyc.2008.71.2.134

Schumacher, S., Niemeyer, H., Engel, S., Cwik, J. C., Laufer, S., Klusmann, H., \& Knaevelsrud, C. (2019). HPA axis regulation in posttraumatic stress disorder: A meta-analysis focusing on potential moderators. Neuroscience and Biobehavioral Reviews, 100, 35-57. https://doi.org/10.1016/j.neubiorev.2019.02.005

Scott, J. C., Matt, G. E., Wrocklage, K. M., Crnich, C., Jordan, J., Southwick, S. M., ... Schweinsburg, B. C. (2015). A quantitative meta-analysis of neurocognitive functioning in posttraumatic stress disorder. Psychological Bulletin, 141(1), 105-140. https://doi.org/ 10.1037/a0038039

Selemon, L. D., Young, K. A., Cruz, D. A., \& Williamson, D. E. (2019). Frontal lobe circuitry in posttraumatic stress disorder. Chronic Stress, 3, 1-17. https://doi.org/10.1177/2470547019850166

Semkovska, M., \& Ahern, E. (2017). Online neurocognitive remediation therapy to improve cognition in community-living individuals with a history of depression: A pilot study. Internet Interventions, 9, 714. https://doi.org/10.1016/j.invent.2017.04.003

Shah, A. J., Lampert, R., Goldberg, J., Veledar, E., Bremner, J. D., \& Vaccarino, V. (2013). Posttraumatic stress disorder and impaired autonomic modulation in male twins. Biological Psychiatry, 73(11), 1103-1110. https://doi.org/10.1016/j.biopsych.2013.01.019

Shalev, A., Liberzon, I., \& Marmar, C. (2017). Post-traumatic stress disorder. The New England Journal of Medicine, 376(25), 2459-2469. https://doi.org/10.1056/NEJMra1612499

Sherin, J. E., \& Nemeroff, C. B. (2011). Post-traumatic stress disorder: The neurobiological impact of psychological trauma. Dialogues in Clinical Neuroscience, 13(3). 263-278.

Sheynin, J., \& Liberzon, I. (2017). Circuit dysregulation and circuit-based treatments in posttraumatic stress disorder. Neuroscience Letters, 649, 133-138. https://doi.org/10.1016/j.neulet.2016.11.014

Shields, G. S., Kuchenbecker, S. Y., Pressman, S. D., Sumida, K. D., \& Slavich, G. M. (2016). Better cognitive control of emotional information is associated with reduced pro- inflammatory cytokine reactivity to emotional stress. Stress, 19(1), 63-68. https://doi.org/10. 3109/10253890.2015.1121983

Shin, L. M., Bush, G., Milad, M. R., Lasko, N. B., Brohawn, K. H., Hughes, K. C., ..., Pitman, R. K. (2011). Exaggerated activation of dorsal anterior cingulate cortex during cognitive interference: A monozygotic twin study of posttraumatic stress disorder. The American Journal of Psychiatry, 168, 979-985. https://doi.org/10. 1176/appi.ajp.2011.09121812

Shucard, J. L., McCabe, D. C., \& Szymanski, H. (2008). An event-related potential study of attention deficits in posttraumatic stress disorder during auditory and visual Go/NoGo continuous performance tasks. Biological Psychology, 79(2), 223-233. https://doi.org/10.1016/j. biopsycho.2008.05.005

Shvil, E., Sullivan, G. M., Schafer, S., Markowitz, J. C., Campeas, M., Wager, T. D., ... Neria, Y. (2014). Sex differences in extinction recall in posttraumatic stress disorder: A pilot fMRI study. Neurobiology of Learning and Memory, 113, 101-108. https://doi. org/10.1016/j.nlm.2014.02.003

Sierk, A., Manthey, A., King, J., Brewin, C. R., Bisby, J. A., Walter, H., ... Daniells, J. K. (2019). Allocentric spatial memory performance predicts intrusive memory severity in posttraumatic stress disorder. Neurobiology of Learning and Memory, 166, 107093. https://doi. org/10.1016/j.nlm.2019.107093

Sierra-Mercado, D., Padilla-Coreano, N., \& Quirk, G. J. (2011). Dissociable roles of prelimbic and infralimbic cortices, ventral hippocampus, and basolateral amygdala in the expression and 
extinction of conditioned fear. Neuropsychopharmacoly, 36, 529538. https://doi.org/10.1038/npp.2010.184

Sijbrandij, M., Engelhard, I. M., Lommen, M. J., Leer, A., \& Baas, J. M. (2013). Impaired fear inhibition learning predicts the persistence of symptoms of posttraumatic stress disorder (PTSD). Journal of Psychiatric Research, 47(12), 1991-1997. https://doi.org/10.1016/ j.jpsychires.2013.09.008

Slavich, G. M., Way, B. M., Eisenberger, N. I., \& Taylor, S. E. (2010). Neural sensitivity to social rejection is associated with inflammatory responses to social stress. Proceedings of the NBational Academy of Sciences of the United States of America, 107(33), 14817-14822. https://doi.org/10.1073/pnas.1009164107

Smith, N. B., Doran, J. M., Sippel, L. M., \& Harpaz-Rotem, I. (2017). Fear extinction and memory reconsolidation as critical components in behavioral treatment for posttraumatic stress disorder and potential augmentation of these processes. Neuroscience Letters, 649, 170-175. https://doi.org/10.1016/j.neulet.2017.01.006

Sneed, J. R., Culang, M. E., Keilp, J. G., Rutherford, B. R., Devanand, D. P., \& Roose, S. P. (2010). Antidepressant medication and executive dysfunction: A deleterious interaction in late-life depression. American Journal of Geriatric Psychiatry, 18(2), 128. https://doi. org/10.1097/JGP.0b013e3181c796d2

Sneed, J. R., Roose, S. P., Keilp, J. G., Krishnan, K. R., Alexopoulos, G. S., \& Sackeim, H. A. (2007). Response inhibition predicts poor antidepressant treatment response in very old depressed patients. The American Journal of Geriatric Psychiatry, 15(7), 553-563. https://doi.org/10.1097/JGP.0b013e3180302513

Sotres-Bayon, F., \& Quirk, G. J. (2010). Prefrontal control of fear: More than just extinction. Current Opinion in Neurobiology, 20(2), 231235. https://doi.org/10.1016/j.conb.2010.02.005

Sparkman, N. L., Kohman, R. A., Garcia, A. K., \& Boehm, G. W. (2005). Peripheral lipopolysaccharide administration impairs two-way active avoidance conditioning in C57BL/6J mice. Physiology \& Behavior, 85(3), 278-288. https://doi.org/10.1016/j.physbeh.2005. 04.015

Speer, K., Upton, D., Semple, S., \& McKune, A. (2018). Systemic lowgrade inflammation in post-traumatic stress disorder: A systematic review. Journal of Inflammation Research, 11, 111-121. https://doi. org/10.2147/JIR.S155903

Spinhoven, P., Penninx, B. W., van Hemert, A. M., de Rooij, M., \& Elzinga, B. M. (2014). Comorbidity of PTSD in anxiety and depressive disorders: Prevalence and shared risk factors. Child Abuse \& Neglect, 38(8), 1320-1330. https://doi.org/10.1016/j.chiabu.2014. 01.017

Sripada, R. K., King, A. P., Garfinkel, S. N., Wang, X., Sripada, C. S., Welsh, R. C., \& Liberzon, I. (2012). Altered resting-state amygdala functional connectivity in men with posttraumatic stress disorder. Journal of Psychiatry \& Neuroscience, 37, 241-249. https://doi. org/10.1503/jpn.110069

Steenkamp, M. M., Litz, B. T., Hoge, C. W., \& Marmar, C. R. (2015). Psychotherapy for military-related PTSD: A review of randomized clinical trials. JAMA, 314(5), 489-500. https://doi.org/10.1001/ jama.2015.8370

Steiger, F., Nees, F., Wicking, M., Lang, S., \& Flor, H. (2015). Behavioral and central correlates of contextual fear learning and contextual modulation of cued fear in posttraumatic stress disorder. International Journal of Psychophysiology, 584-593. https://oi. org/10.1016/j.ijpsycho.2015.06.009

Stein, D. J., Ipser, J. C., Seedat, S., Sager, C., \& Amos, T. (2006). Pharmacotherapy for post traumatic stress disorder (PTSD). Cochrane database of systematic reviews, (1).

Stein, M. B., Jain, S., Giacino, J. T., Levin, H., Dikmen, S., Nelson, L., ... TRACK-TBI Investigators. (2019). Risk of posttrauatic stress disorder and major depression in civilivan patietns after mild traumatic brain injury: A TRACK-TBI study. JAMA Psychiatry, 76(3), 249258. https://doi.org/10.1001/jamapsychiatry.2018.4288
Stein, M. B., Kennedy, C. M., \& Twamley, E. W. (2002). Neuropsychological function in female victims of intimate partner violence with and without posttraumatic stress disorder. Biological Psychiatry, 52, 1079-1088.

Stevens, J. S., Jovanovic, T., Fani, N., Ely, T. D., Glover, E. M., Bradley, B., \& Ressler, K. J. (2013). Disrupted amygdala-prefrontal functional connectivity in civilian women with posttraumatic stress disorder. Journal of Psychiatric Research, 47(10), 1469-1478. https://doi. org/10.1016/j.jpsychires.2013.05.031

Sumner, J. A., Hagan, K., Grodstein, F., Roberts, A. L., Harel, B., \& Koenen, K. C. (2017). Posttraumatic stress disorder symptoms and cognitive function in a large cohort of middle-aged women. Depression and Anxiety, 34(4), 356-366. https://doi.org/10.1002/ da. 22600

Swardfager, W., Lanctot, K., Rothenburg, L., Wong, A., Cappell, J., \& Herrmann, N. (2010). A meta-analysis of cytokines in Alzheimer's disease. Biological Psychiatry, 68(10), 930-941. https://doi.org/10. 1016/j.biopsych.2010.06.012

Swick, D., Cayton, J., Ashley, V., \& Turken, A. U. (2017). Dissociation between working memory performance and proactive interference control in post-traumatic stress disorder. Neuropsychologia, 96, 111-121. https://doi.org/10.1016/j.neuropsychologia.2017.01.005

Swick, D., Honzel, N., Larsen, J., \& Ashley, V. (2013). Increased response variability as a marker of executive dysfunction in veterans with post-traumatic stress disorder. Neuropsychologia, 51(14), 3033-3040. https://doi.org/10.1016/j.neuropsychologia.2013.10. 008

Swick, D., Honzel, N., Larsen, J., Ashley, V., \& Justus, T. (2012). Impaired response inhibition in veterans with post-traumatic stress disorder and mild traumatic brain injury. Journal of the International Neuropsychological Society, 18(5), 917-926. https://doi.org/10. 1017/S1355617712000458

Tan, G., Dao, T. K., Farmer, L., Sutherland, R. J., \& Gevirtz, R. (2011). Heart rate variability (HRV) and posttraumatic stress disorder (PTSD): A pilot study. Applied Psychophysiology and Biofeedback, 36(1), 27-35. https://doi.org/10.1007/s10484-0109141-y

Tang, Y., Ma, Y., Fan, Y., Feng, H., Wang, J., Feng, S., ... Fan, M. (2009). Central and autonomic nervous system interaction is altered by short-term mediation. Proceedings of the Naional Academy of Science of the United States of America, 106(22), 8865-8870.

Tang, Y. Y., Tang, Y., Tang, R., \& Lewis-Peacock, J. A. (2017). Brief mental training reorganizes large-scale brain networks. Frontiers in Systems Neuroscience, 11, 6. https://doi.org/10.3389/fnsys.2017. 00006

Tangestani Fard, M., \& Stough, C. (2019). Review and hypothesized model of the mechanisms that underpin the relationship between inflammation and cognition in the elderly. Frontiers in Aging Neuroscience, 11, 56. https://doi.org/10.3389/fnagi.2019.00056

Taren, A. A., Gianaros, P. J., Greco, C. M., Lindsay, E. K., Fairgrieve, A., Brown, K. W., ... Creswell, J. D. (2017). Mindfulness Meditation Training and Executive Control Network Resting State Functional Connectivity: A Randomized Controlled Trial. Psychosomatic Medicine, 79(6), 674-683. https://doi.org/10.1097/PSY. 0000000000000466

Teper, R., Segal, Z. V., \& Inzlicht, M. (2013). Inside the mindful mind. Current Directions in Psychological Science, 22(6), 449-454. https://doi.org/10.1177/0963721413495869

Thayer, J., Yamamoto, S., \& Brosschot, J. (2010). The relationship of autonomic imbalance, heart rate variability and cardiovascular disease risk factors. International Journal of Cardiology, 141(2), 122131. https://doi.org/10.1016/j.ijcard.2009.09.543

Thayer, J. F., Hansen, A. L., Saus-Rose, E., \& Johnsen, B. H. (2009). Heart rate variability, prefrontal neural function, and cognitive performance: The neurovisceral integration perspective on self- 
regulation, adaptation, and health. Annals of Behavioral Medicine, 37(2), 141-153. https://doi.org/10.1007/s12160-009-9101-z

Trapero, I., \& Cauli, O. (2014). Interleukin 6 and cognitive dysfunction. Metabolic Brain Disease, 29(3), 593-608. https://doi.org/10.1007/ s11011-014-9551-2

Tsai, S. J. (2017). Effects of interleukin-1beta polymorphisms on brain function and behavior in healthy and psychiatric disease conditions. Cytokine \& Growth Factor Reviews, 37, 89-97. https://doi.org/10. 1016/j.cytogfr.2017.06.001

Tuerk, P. W., Wangelin, B., Rauch, S. A. M., Dismuke, C. E., Yoder, M., Myrick, H., ... Acierno, R. (2013). Health service utilization before and after evidence-based treatment for PTSD. Psychological Services, 10(4), 401-409. https://doi.org/10.1037/a0030549

Twamley, E. W., Allard, C. B., Thorp, S. R., Norman, S. B., Hami Cissell, S., Hughes Berardi, K., ... Stein, M. B. (2009). Cognitive impairment and functioning in PTSD related to intimate partner violence. Journal of the International Neuropsychological Society, 15(6), 879-887. https://doi.org/10.1017/S135561770999049X

van Rooij, S. J., Geuze, E., Kennis, M., Rademaker, A. R., \& Vink, M. (2015). Neural correlates of inhibition and contextual cue processing related to treatment response in PTSD. Neuropsychopharmacology, 40(3), 667-675. https://doi.org/10.1038/npp.2014.220

van Rooij, S. J., Kennis, M., Vink, M., \& Geuze, E. (2016). Predicting treatment outcome in PTSD: A longitudinal functional MRI study on trauma-unrelated emotional processing. Neuropsychopharmacology, 41(4), 1156-1165. https://doi.org/10. 1038/npp.2015.257

van Zuiden, M., Kavelaars, A., Geuze, E., Olff, M., \& Heijnen, C. J. (2013). Predicting PTSD: pre-existing vulnerabilities in glucocorticoid-signaling and implications for preventive interventions. Brain, Behavior, and Immunity, 30, 12-21. https://doi.org/ 10.1016/j.bbi.2012.08.015

VanElzakker, M. B., Dahlgren, M. K., Davis, F. C., Dubois, S., \& Shin, L. M. (2014). From Pavlov to PTSD: The extinction of conditioned fear in rodents, humans, and in anxiety disorders. Neurobiology of Learning and Memory, 113, 3-18. https://doi.org/10.1016/j.nlm. 2013.11.014

Vasterling, J. J., Duke, L. M., Brailey, K., Constans, J. I., Allain, A. N., \& Sutker, P. B. (2002). Attention, learning, and memory performances and intellectual resources in Vietnam veterans: PTSD and no disorder comparisons. Neuropsychology, 16(1), 5-14.

Vecchiarelli, H. A., Gandhi, C. P., Gray, J. M., Morena, M., Hassan, K. I., \& Hill, M. N. (2016). Divergent responses of inflammatory mediators within the amygdala and medial prefrontal cortex to acute psychological stress. Brain, Behavior, and Immunity, 51, 70-91. https:// doi.org/10.1016/j.bbi.2015.07.026

Veer, I. M., Oei, N. Y. L., van Buchen, M. A., Spinhoven, P., Elzinga, B. M., \& Rombauts, S. A. R. B. (2015) Evidence for smaller right amygdala volumes in posttraumatic stress disorder following childhood trauma. Psychiatry Research: Neuroimaging, 233(3), 436442. https://doi.org/10.1016/j.pscychresns.2015.07.016

Vidal-Gonzalez, I., Vidal-Gonzalez, B., Rauch, S. L., \& Quirk, G. (2006). Microstimulation reveals opposing influences of prelimbic and infralimbic cortex on the expression of conditioned fear. Learning \& Memory, 13, 728-733. https://doi.org/10.1101/lm.306106

Vollmer, L. L., Schmeltzer, S. S., Schurdak, J., Ahlbrand, R., Rush, J., Dolgas, C. M., ... Sah, R. (2016). Neuropeptide Y impairs retrieval of extinguished fear and modulates excitability of neurons in the infralimbic prefrontal cortex. Journal of Neuroscience, 36(4), 1306-1315. https://doi.org/10.1523/JNEUROSCI.4955-13.2016

Walker, K. A., Gottesman, R. F., Wu, A., Knopman, D. S., Gross, A. L., Modley, T. H. Jr., ... Windham, B. G. (2019). Systemic inflammation during midlife and cognitive change over 20 years: The ARIC Study. Neurology, 92(11), e1256-e1267. https://doi.org/10.1212/ WNL.0000000000007094
Wang, Z., Caughron, B., \& Young, M. R. I. (2017). Posttraumatic stress disorder: An immunological disorder? Frontiers in Psychiatry, 8, 222. https://doi.org/10.3389/fpsyt.2017.00222

Wang, Z., Neylan, T. C., Mueller, S. G., Lenoci, M., Truran, D., Marmar, C. R., ... Schuff, N. (2010). Magnetic resonance imaging of hippocampal subfields in posttraumatic stress disorder. Archives of General Psychiatry, 67(3), 296-303. https://doi.org/10.1001/ archgenpsychiatry.2009.205

Wang, Z., \& Young, R. I. (2016). PTSD, a disorder with an immunological component. Frontiers in Immunology, 7, 219. https://doi.org/10. 3389/fimmu.2016.00219

Wessel, I., Merckelbach, H., \& Dekkers, T. (2002). Autobiographical memory specificity, intrusive memory, and general memory skills in Dutch-Indonesian survivors of the World War II era. Journal of Traumatic Stress, 15(3), 227-234.

Whitworth, J. W., Nosrat, S., SantaBarbara, N. J., \& Ciccolo, J. T. (2019). Feasibility of Resistance Exercise for Posttraumatic Stress and Anxiety Symptoms: A Randomized Controlled Pilot Study. Journal of Traumatic Stress. Advance online publication. https:// doi.org/10.1002/jts.22464

Wicking, M., Steiger, F., Nees, F., Diener, S. J., Grimm, O., Ruttorf, M., ... Flor, H. (2016). Deficient fear extinction memory in posttraumatic stress disorder. Neurobiology of Learning and Memory, 136, 116 126. https://doi.org/10.1016/j.nlm.2016.09.016

Wild, J., \& Gur, R. C. (2008). Verbal memory and treatment response in post-traumatic stress disorder. The British Journal of Psychiatry, 193(3), 254-255. https://doi.org/10.1192/bjp.bp.107.045922

Williamson, J. B., Porges, E. C., Lamb, D. G., \& Porges, S. W. (2014). Maladaptive autonomic regulation in PTSD accelerates physiological aging. Frontiers in Psychology, 5, 1571. https://doi.org/10.3389/ fpsyg.2014.01571

Wolf, O. T. (2008). The influence of stress hormones on emotional memory: Relevance for psychopathology. Acta Psychologica, 127(3), 513-531. https://doi.org/10.1016/j.actpsy.2007.08.002

Wolinsky, F. D., Vander Weg, M. W., Martin, R., Unverzagt, F. W., Ball, K. K., Jones, R. N., \& Tennstedt, S. L. (2009). The effect of speedof-processing training on depressive symptoms in ACTIVE. Journals of Gerontology. Series A, Biological Sciences and Medical Sciences, 64(4), 468-472. https://doi.org/10.1093/gerona/ gln044

Woodward, N. D., Duffy, B., \& Karbasforoushan, H. (2013). Prefrontal cortex activity during response selection predicts processing speed impairment in schizophrenia. Journal of the International Neuropsychological Society, 19(7), 782-791. https://doi.org/10. 1017/S1355617713000532

Woon, F. L., Sood, S., \& Hedges, D. W. (2010). Hippocampal volume deficits associated with exposure to psychological trauma and posttraumatic stress disorder in adults: A meta-analysis. Progress in Neuro-Psychopharmacology and Biological Psychiatry, 34(7), 1181-1188. https://doi.org/10.1016/j.pnpbp.2010.06.016

Wu, J., Yuan, Y., Cao, C., Zhang, K., Wang, L., \& Zhang, L. (2015). The relationship between response inhibition and posttraumatic stress symptom clusters in adolescent earthquake survivors: An eventrelated potential study. Scientific Reports, 5, 8844. https://doi.org/ 10.1038/srep08844

Yanagisawa, H., Dan, I., Tsuzuki, D., Kato, M., Okamoto, M., Kyutoku, Y., \& Soya, H. (2010). Acute moderate exercise elicits increased dorsolateral prefrontal activation and improves cognitive performance with Stroop test. NeuroImage, 50(4), 1702-1710. https:// doi.org/10.1016/j.neuroimage.2009.12.023

Yang, C., Shen, J., Hong, T., Hu, T. T., Li, Z. J., Zhang, H. T., ... Yang, J. J. (2013). Effects of ketamine on lipopolysaccharide-induced depressive-like behavior and the expression of inflammatory cytokines in the rat prefrontal cortex. Molecular Medicine Reports, 8(3), 887890. https://doi.org/10.3892/mmr.2013.1600 
Yehuda, R. (2002). Post-traumatic stress disorder. The New England Journal of Medicine, 346(2), 108-114.

Yehuda, R., Golier, J. A., Halligan, S. L., \& Harvey, P. D. (2004). Learning and memory in Holocaust survivors with posttraumatic stress disorder. Biological Psychiatry, 55(3), 291-295. https://doi. org/10.1016/s0006-3223(03)00641-3

Yehuda, R., Golier, J. A., Tischler, L., Stavitsky, K., \& Harvey, P. D. (2005). Learning and memory in aging combat veterans with PTSD. Journal of Clinical and Experimental Neuropsychology, 27(4), 504-515. https://doi.org/10.1080/138033990520223

Yirmiya, R., \& Goshen, I. (2011). Immune modulation of learning, memory, neural plasticity and neurogenesis. Brain, Behavior, and Immunity, 25(2), 181-213. https://doi.org/10.1016/j.bbi.2010.10. 015

Zelikowsky, M., Bissiere, S., Hast, T. A., Bennett, R. Z., Abdipranoto, A., Vissel, B., Fanselow, M. S. (2013). Prefrontal microcircuit underlies contextual learning after hippocampal loss. Proceedings of the National Academy of Sciences of the United States of America, 110(24), 9938-43. https://doi.org/10.1073/pnas.1301691110

Zhang, J., Tan, Q., Yin, H., Zhang, X., Huan, Y., Tang, L., ... Li, L. (2011). Decreased gray matter volume in the left hippocampus and bilateral calcarine cortex in coal mine flood disaster survivors with recent onset PTSD. Psychiatry Research, 192(2), 84-90. https://doi. org/10.1016/j.pscychresns.2010.09.001

Zhu, H., Li, Y., Yuan, M., Ren, Z., Yuan, C., Meng, Y., ... Zhang, W. (2019). Increased functional segregation of brain network associated with symptomatology and sustained attention in chronic posttraumatic stress disorder. Journal of Affective Disorders, 247, 183191. https://doi.org/10.1016/j.jad.2019.01.012

Zlomuzica, A., Would, M. L., Machulska, A., Kleimt, K., Dietrich, L., Wolf, O. T., ... Margraf, J. (2018). Deficits in episodic memory and mental time travel in patients with posstraumatic stress disorder. Progress in Neuro-Psychopharmacology \& Biological Psychiatry, 83, 42-54. https://doi.org/10.1016/j.pnpbp.2017.12.014

Zucker, T. L., Samuelson, K. W., Muench, F., Greenberg, M. A., \& Gevirtz, R. N. (2009). The effects of respiratory sinus arrhythmia biofeedback on heart rate variability and posttraumatic stress disorder symptoms: a pilot study. Applied Psychophysiology and Biofeedback, 34(2), 135-143. https://doi.org/10.1007/s10484-0099085-2

Publisher's note Springer Nature remains neutral with regard to jurisdictional claims in published maps and institutional affiliations. 